\title{
Analysis of the Lactobacillus casei supragenome and its influence in species evolution and lifestyle adaptation
}

\author{
Jeff R Broadbent ${ }^{1 *}$, Eric C Neeno-Eckwall ${ }^{2}$, Buffy Stahl ${ }^{3}$, Kanokwan Tandee ${ }^{4}$, Hui Cai ${ }^{4,5}$, Wesley Morovic ${ }^{3}$, \\ Philippe Horvath ${ }^{6}$, Jessie Heidenreich ${ }^{4}$, Nicole T Perna ${ }^{7}$, Rodolphe Barrangou ${ }^{3}$ and James L Steele ${ }^{4}$
}

\begin{abstract}
Background: The broad ecological distribution of $L$. casei makes it an insightful subject for research on genome evolution and lifestyle adaptation. To explore evolutionary mechanisms that determine genomic diversity of L. casei, we performed comparative analysis of $17 \mathrm{~L}$. casei genomes representing strains collected from dairy, plant, and human sources.

Results: Differences in L. casei genome inventory revealed an open pan-genome comprised of 1,715 core and 4,220 accessory genes. Extrapolation of pan-genome data indicates L. casei has a supragenome approximately 3.2 times larger than the average genome of individual strains. Evidence suggests horizontal gene transfer from other bacterial species, particularly lactobacilli, has been important in adaptation of L. casei to new habitats and lifestyles, but evolution of dairy niche specialists also appears to involve gene decay.

Conclusions: Genome diversity in L. casei has evolved through gene acquisition and decay. Acquisition of foreign genomic islands likely confers a fitness benefit in specific habitats, notably plant-associated niches. Loss of unnecessary ancestral traits in strains collected from bacterial-ripened cheeses supports the hypothesis that gene decay contributes to enhanced fitness in that niche. This study gives the first evidence for a $L$. casei supragenome and provides valuable insights into mechanisms for genome evolution and lifestyle adaptation of this ecologically flexible and industrially important lactic acid bacterium. Additionally, our data confirm the Distributed Genome Hypothesis extends to non-pathogenic, ecologically flexible species like L. casei.
\end{abstract}

Keywords: Lactobacillus casei, Lactic acid bacteria, Comparative genomics, Pan-genome, Supragenome, Evolution, Adaptation

\section{Background}

Lactic acid bacteria (LAB) constitute a group of Grampositive, non-sporulating, nutritionally fastidious, and strictly fermentative bacteria that produce lactic acid as the major end product from carbohydrate [1]. Lactobacillus, which currently holds 177 species [http://www.bacterio. cict.fr/], is by far the largest and most diverse genus of LAB. Different species of lactobacilli are important components of the oral cavity as well as the gastrointestinal and reproductive tracts of vertebrates,

\footnotetext{
* Correspondence: jeff.broadbent@usu.edu

'Utah State University Department of Nutrition, Dietetics, and Food Sciences, 8700 Old Main Hill, Logan, UT 84322-8700, USA

Full list of author information is available at the end of the article
}

while others are indigenous to milk, plant material, and meat environments [2]. Many play important roles in both traditional and commercial-scale food and feed fermentations, or food spoilage.

A few species of Lactobacillus show remarkable ecological adaptability and may be recovered from a variety of diverse habitats [2]. Lactobacillus casei, for example, has been isolated from raw and fermented dairy (especially cheese, where they often emerge as the dominant adventitious or "nonstarter" species during ripening [3]) and plant materials (e.g., wine, silage, pickles, and kimchi), as well as the oral cavity and gastrointestinal tracts of humans and animals [2]. As an aside, debate over the taxonomy of L. casei in recent years has led to

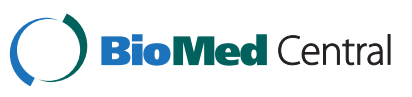


interchangeable use of $L$. casei and L. paracasei in the literature. All of the strains included in this study show $>99 \%$ identity to the $16 \mathrm{~S}$ rRNA sequence of $L$. casei ATCC 334, which is the current type strain for L. paracasei [4].

The broad ecological distribution of $L$. casei reflects a metabolic flexibility that has fueled widespread application of the species in the food and health industries; different strains are employed as acid-producing starter cultures for milk fermentation, as adjunct cultures to accelerate or intensify flavor development in bacterialripened cheeses, and as probiotics to enhance human or animal health [5-7]. The Food and Agriculture Organization and the World Health Organization of the United Nations define probiotics as "live microorganisms which when administered in adequate amounts confer a health benefit on the host" [8]. Strains used as starter cultures or probiotics must, of course, be nonpathogenic to humans even when consumed in very high numbers (e.g., $\left.10^{9}-10^{10} \mathrm{cfu} / \mathrm{dose}\right)$. Thus, the wide ecological distribution of $L$. casei makes this species a particularly interesting and relevant subject for research on genetic diversity, genome evolution, and lifestyle adaptation.

Bacterial genome evolution and adaptation are thought to occur via three major processes: 1) modification of existing genes by mutation with vertical inheritance [9-12]; 2) acquisition of exogenous genes or gene clusters by bacteria through horizontal gene transfer (HGT) that impart a fitness benefit [13-17]; and 3) deletion or decay of genes that no longer confer a fitness benefit [18-20]. Comparative genome analysis of lactobacilli and other LAB has shown that all three mechanisms have contributed to the adaptation of these microbes to new habitats and lifestyles, but gene decay and acquisition by HGT appear to be especially dominant forces [21-28]. In L. casei and many other LAB, genome evolution is expected to reflect adaptation of the species to dynamic, nutritionally variable and ancient environments, such as the gastrointestinal tract and plant materials, as well as relatively recent expansion into a more constant and nutrient-rich milk-based niche. Not surprisingly, comparative genome analysis between $L$. casei ATCC 334 and other sequenced lactobacilli confirmed L. casei has features, including a relatively high number of carbohydrate-related genes and IS elements [21,28], which are consistent with a metabolically and genetically versatile lifestyle $[28,29]$.

The evolutionary history of $L$. casei has been viewed through its population structure; multi-locus sequence typing (MLST) of $40 \mathrm{~L}$. casei strains isolated from different niches indicated the species had diverged into three lineages [30]. Separation of two major clusters occurred approximately 1.5 million years ago; one large cluster contained strains recovered from human, plant, and dairy sources, while the second and smaller cluster was predominantly comprised of corn silage isolates. In contrast, the third major cluster included 15 strains that had been isolated from cheese in the United States, Australia, and Europe, and was predicted to reflect recent divergence of strains that were highly specialized for this relatively new ecological niche (manufacture of cheese is thought to have begun $\sim 8,000$ years ago) [30,31]. This cluster of cheese specialists was also revealed in a follow up study that explored L. casei genetic diversity by comparative genome hybridization $(\mathrm{CGH})$ of 21 strains against an ATCC 334 whole genome microarray [28]. That work further suggested that adaptation to the cheese environment had been accompanied by extensive decay of genes involved in carbohydrate utilization and transcriptional regulation [28]. Metabolic simplification via the loss of genes for carbohydrate metabolism has been associated with adaptation of other LAB species to the nutrient-rich milk environment [32-35]. Intriguingly, many of the genes that $L$. casei cheese specialists lacked were associated with genomic islands postulated to function in lifestyle adaptation of other L. casei strains [28].

$\mathrm{CGH}$ data for the 21 strains as well as comparative genome analysis between strains ATCC 334 and BL23 identified numerous hypervariable regions and genomic islands, respectively, some of which showed an atypical base composition that is commonly associated with gene acquisition by HGT [28]. The diversity and distribution of these regions among different strains indicated that: i) there was a large pool of accessory genes in the population; ii) most $L$. casei strains were likely niche generalists that could exploit a variety of habitats and tolerate a wide range of environmental conditions; and iii) HGT has played a significant role in the evolution, lifestyle adaptation, and metabolic diversity of L. casei [28]. However, these conclusions were softened by the knowledge that microarray-based CGH analysis cannot identify genes that may be present in the test strain but absent from the reference strain, and because the ecological origin of strain BL23 is unclear [36].

In recent years, the availability of multiple genome sequences for a single species has demonstrated that a number of pathogenic bacteria possess an extensive pangenome or "supragenome" that may be several fold larger than the genome of any single strain [22,23,25,37-40]. This discovery has given rise to the Distributed Genome Hypothesis (DGH), which postulates that access to a supragenome through homologous recombination allows individual strains to rapidly shuffle their genetic information and overcome host defense responses [41]. Although the DGH has been almost exclusively applied to describe genome evolution in pathogens, the circumstances upon which it is founded (i.e., cells aggregate into polyclonal or polymicrobial biofilms which facilitates HGT) [41] are 
widespread in the microbial world. Baumdicker et al. [42] recently showed the DGH extended to nonpathogenic bacteria, and it was our hypothesis that a distributed supragenome would drive genome evolution and lifestyle adaptation in an ecologically flexible species such as L. casei.

To test this hypothesis, we collected draft sequences for 12 strains that had been isolated from dairy $(\mathrm{n}=5)$, plant $(n=5)$, or human $(n=2)$ sources that appear to provide broad representation for the genetic diversity in L. casei $[28,30]$, and performed comparative genome analysis between these strains plus the complete sequences from 5 additional L. casei strains (ATCC 334, BL23, Zhang, BD-II, and LC2W) in the public database [21,43-46].

\section{Results and discussion}

\section{L. casei genome features}

Genome features of the 17 L. casei strains included in the study, which provide a broad representation of genetic, ecological, and geographical diversity in the species, are presented in Tables 1 and 2. The 12 new draft sequences had a range of coverage between $17 \mathrm{X}$ and 133X $($ mean $=31.6 \mathrm{X})$ and ranged in total contig number from 28-167 (mean = 99 contigs) $($ Table 1$)$. Using a set of only three closed genome references (ATCC 334, BL23, and Zhang), we were able to determine orientation and order the contigs of each draft. The contig numbers listed in Table 1 were obtained after contigs were ordered and oriented in Mauve and the draft was aligned end-to-end based on the advanced order, which reduced the number of contigs obtained from the de novo assembly by an average of $20 \%$ (data not shown). Each of the genomes was assembled into scaffolds based on the placed and unplaced contigs from Mauve, with the unplaced contigs being ordered by name at the end of the scaffold.

Although the final contig order was not independently validated for all 12 draft genomes, an optical restriction map [47] was used as a reference to validate assembly of the Lpc-37 genome by this approach (see Additional file 1: Figure S1 in supplementary online material). The overall arrangement of the contig order for Lpc-37 was done using progressive Mauve, and alignment of the contigs to the optical map demonstrates that the method of assembly and ordering yielded a well ordered draft, with only a few major gaps. The optical map gave an estimated genome size of 3,014,302 bp with a total concatenated ordered draft length of 2,916,119 bp ( 97\% coverage). Based on the alignment between optical map and draft assembly, the size difference is likely derived from 3 major sequence gaps approximately 30, 70, and $10 \mathrm{~kb}$ in size (Additional file 1: Figure S1).

The number of predicted CDS features in each genome ranged from 2,643 to 3,262, with an overall GC content of 46.1-46.6\% (Table 1). Comparative genomics of the resulting architecture revealed synteny was relatively high across the L. casei genomes, with several large blocks of highly conserved gene content across all 17 L. casei strains (Figure 1). These data also indicate

Table 1 Genome features of the 17 L. casei strains used in the study ${ }^{1}$

\begin{tabular}{|c|c|c|c|c|c|c|c|c|c|c|}
\hline Strain & Origin & $\begin{array}{c}\text { Ave. } \\
\text { coverage }\end{array}$ & $\begin{array}{l}\text { Number } \\
\text { contigs }\end{array}$ & $\begin{array}{l}\text { Total bp } \\
\text { in contigs }\end{array}$ & $\%$ GC & $\begin{array}{l}\text { Plasmid } \\
\text { DNA }\end{array}$ & GenBank accession number & $\begin{array}{c}\text { CDS } \\
\text { features }\end{array}$ & tRNAs & $\begin{array}{l}\text { Reference } \\
\text { or source }\end{array}$ \\
\hline ATCC 334 & Swiss cheese & $8 X$ & 2 & $2,924,325$ & 46.6 & 1 & NC_008526 and NC_008502 & 2,643 & 59 & {$[21]$} \\
\hline $\bar{M} 36$ & Cheddar cheese & $19 X$ & 78 & $3,152,126$ & 46.3 & & AFYO00000000 & 3,001 & 57 & {$[30]$} \\
\hline UW1 & Cheddar cheese & $21 X$ & 143 & $2,865,538$ & 46.4 & & AFYR00000000 & 2,826 & 54 & {$[30]$} \\
\hline UW4 & Cheddar cheese & $22 X$ & 122 & $2,758,298$ & 46.4 & & AFYS00000000 & 2,689 & 57 & {$[30]$} \\
\hline Zhang & Koumiss & $6 X$ & 2 & $2,898,335$ & 46.4 & 1 & NC_014334 and NC_011352 & 2,723 & 59 & {$[44]$} \\
\hline$\overline{\mathrm{BD}-\mathrm{II}}$ & Koumiss & $381 X$ & 2 & $3,127,288$ & 46.3 & 1 & CP002618 and CP002619 & 3,069 & 59 & {$[45]$} \\
\hline $\mathrm{LC} 2 \mathrm{~W}$ & Dairy product & $98 X$ & 2 & $3,077,434$ & 46.3 & 1 & CP002616 and CP002617 & 3,019 & 58 & {$[46]$} \\
\hline$\overline{L C-10}$ & Dairy product & $24 X$ & 76 & $2,951,397$ & 46.4 & & AFYT00000000 & 2,780 & 58 & This study \\
\hline Lpc-37 & Dairy product & $133 X$ & 150 & $3,075,253$ & 46.3 & & AFYU00000000 & 2,861 & 58 & This study \\
\hline $\mathrm{BL} 23$ & Unknown & $34 X$ & 1 & $3,079,196$ & 46.3 & 0 & NC_010999 & 2,977 & 60 & [43] \\
\hline $12 \mathrm{~A}$ & Corn silage & $23 x$ & 28 & $2,885,619$ & 46.4 & & AFYJ00000000 & 2,702 & 57 & {$[30]$} \\
\hline $21 / 1$ & Corn silage & $26 X$ & 75 & $3,215,878$ & 46.2 & & AFYK00000000 & 3,080 & 57 & {$[30]$} \\
\hline $32 \mathrm{G}$ & Corn silage & $17 X$ & 42 & $3,011,496$ & 46.4 & & AFYL00000000 & 2,920 & 57 & {$[30]$} \\
\hline A2-362 & Wine & $24 X$ & 167 & $3,361,266$ & 46.1 & & AFYM00000000 & 3,262 & 58 & {$[28]$} \\
\hline UCD174 & Wine & $25 X$ & 116 & $3,071,637$ & 46.4 & & AFYQ00000000 & 3,020 & 57 & {$[28]$} \\
\hline T71499 & Human blood & $30 x$ & 55 & $3,000,122$ & 46.2 & & AFYP00000000 & 2,796 & 57 & [30] \\
\hline CRF28 & Human blood & $24 X$ & 57 & $3,036,548$ & 46.3 & & AFYN00000000 & 2,911 & 54 & [30] \\
\hline
\end{tabular}

'Determined for all genomes using the ASAP database (https://asap.ahabs.wisc.edu). 
Table 2 Orthologous clusters in the L. casei supragenome ${ }^{1}$

\begin{tabular}{|c|c|c|c|c|c|c|c|}
\hline \multirow[t]{2}{*}{ Strain } & \multicolumn{7}{|c|}{ Orthologous clusters } \\
\hline & Total & Core & Pan & Distributed & Unique & $\%$ Non-core & $\%$ Unique \\
\hline ATCC 334 & 2,511 & & & 796 & 54 & 32 & 2 \\
\hline M36 & 2,918 & & & 1,203 & 91 & 41 & 3 \\
\hline UW1 & 2,700 & 1,715 & 5,935 & 985 & 203 & 36 & 8 \\
\hline UW4 & 2,593 & & & 878 & 187 & 34 & 7 \\
\hline Zhang & 2,649 & & & 934 & 49 & 35 & 2 \\
\hline BD-II & 2,936 & & & 1,221 & 19 & 42 & 1 \\
\hline BL23 & 2,866 & & & 1,151 & 54 & 40 & 2 \\
\hline $\mathrm{LC} 2 \mathrm{~W}$ & 2,893 & & & 1,178 & 29 & 41 & 1 \\
\hline LC-10 & 2,715 & & & 1,000 & 104 & 37 & 4 \\
\hline$\underline{\mathrm{Lpc}-37}$ & 2,799 & & & 1,084 & 37 & 39 & 1 \\
\hline $12 \mathrm{~A}$ & 2,651 & & & 936 & 47 & 35 & 2 \\
\hline $21 / 1$ & 2,958 & & & 1,243 & 183 & 42 & 6 \\
\hline $32 \mathrm{G}$ & 2,821 & & & 1,106 & 174 & 39 & 6 \\
\hline $\mathrm{A} 2-362$ & 3,108 & & & 1,393 & 326 & 45 & 10 \\
\hline UCD174 & 2,879 & & & 1,164 & 240 & 40 & 8 \\
\hline T71499 & 2,745 & & & 1,030 & 85 & 38 & 3 \\
\hline CRF28 & 2,851 & & & 1,136 & 148 & 40 & 5 \\
\hline
\end{tabular}

'Downloaded from ASAP (www.asap.ahabs.wisc.edu) September 19, 2011.

that genome size differences were not due to major chromosomal insertions, deletions or re-arrangements.

Sequence homology was determined even more accurately when strains were aligned based on gene content (Figure 2), so that most of the diversity is observed as indels. As expected, the number of Locally Collinear Blocks (LCBs) detected using the progressive Mauve alignment increased with the number of genomes compared. Hierarchical clustering of strains based on overall gene content yielded a dendrogram with 6 clusters, designated A-F (Figure 2). When members of each cluster were aligned to each other or to their closest reference genome, the number of LCBs was reduced, and the overall sequence homology detected between the strains was apparent based on the height of the similarity profile within each LCB (Figure 2). No major genomic rearrangements were detected within any of the draft sequences. Content conservation was even higher within clusters (Figure 2), most notably for clusters $\mathrm{E}$ and $\mathrm{F}$. Even within clusters $B$ and $C$, which contain 7 and 3 strains, respectively, overall synteny was high with mostly localized polymorphic content (Figure 2).

Comparison of the gene content-based dendrogram (Figure 2) to an MLST-based phylogenetic tree for the 17 L. casei strains examined in this study (Figure 3) revealed similar clustering for strains in gene content clusters A, E, F, and parts of B and C. However, MLSTderived relationships among the remaining strains did not resemble those derived from overall gene content. The basis for this observation is well understood;
MLST-based phylogeny reflects relatively slow genome evolution caused by point mutations and selective pressure, whereas the gene content dendrogram captures more rapid (and unpredictable) large-scale insertion and deletion events. Thus, variations between gene contentand MLST-based dendrograms are expected in bacterial species like $L$. casei that display frequent intra-species recombination $[22,25,28,30]$.

\section{Characterization of the $L$. casei core and supragenome}

Comparative genome analysis between the five complete and $12 \mathrm{draft}$ genomes provided new insights to the genetic diversity of $L$. casei. The $L$. casei genome encodes an average of 2,800 $( \pm 151)$ orthologous clusters, of which 1,715 were common to all 17 strains analyzed ("core genome"). Graphing the numbers of core and total features ("pan-genome", or total number of different genes found within a species) as a function of the number of strains sequenced revealed the slope for core gene number was approaching an asymptote, whereas the pangenome continued to expand even after compilation of 17 genomes (Figure 4A). Overall, differences in L. casei genome inventory reveal an open pan-genome comprised of 1,715 core and 4,220 accessory orthologous clusters identified to date, including a large number of unique orthologous clusters in each strain (range $=19$ to 326, with an average of 119) (Table 2 and Figure 4B). Extrapolation of these data using the binomial mixture model described by Snipen et al. [48] yields an estimated core genome of 1,600 orthologous clusters and a pan- 


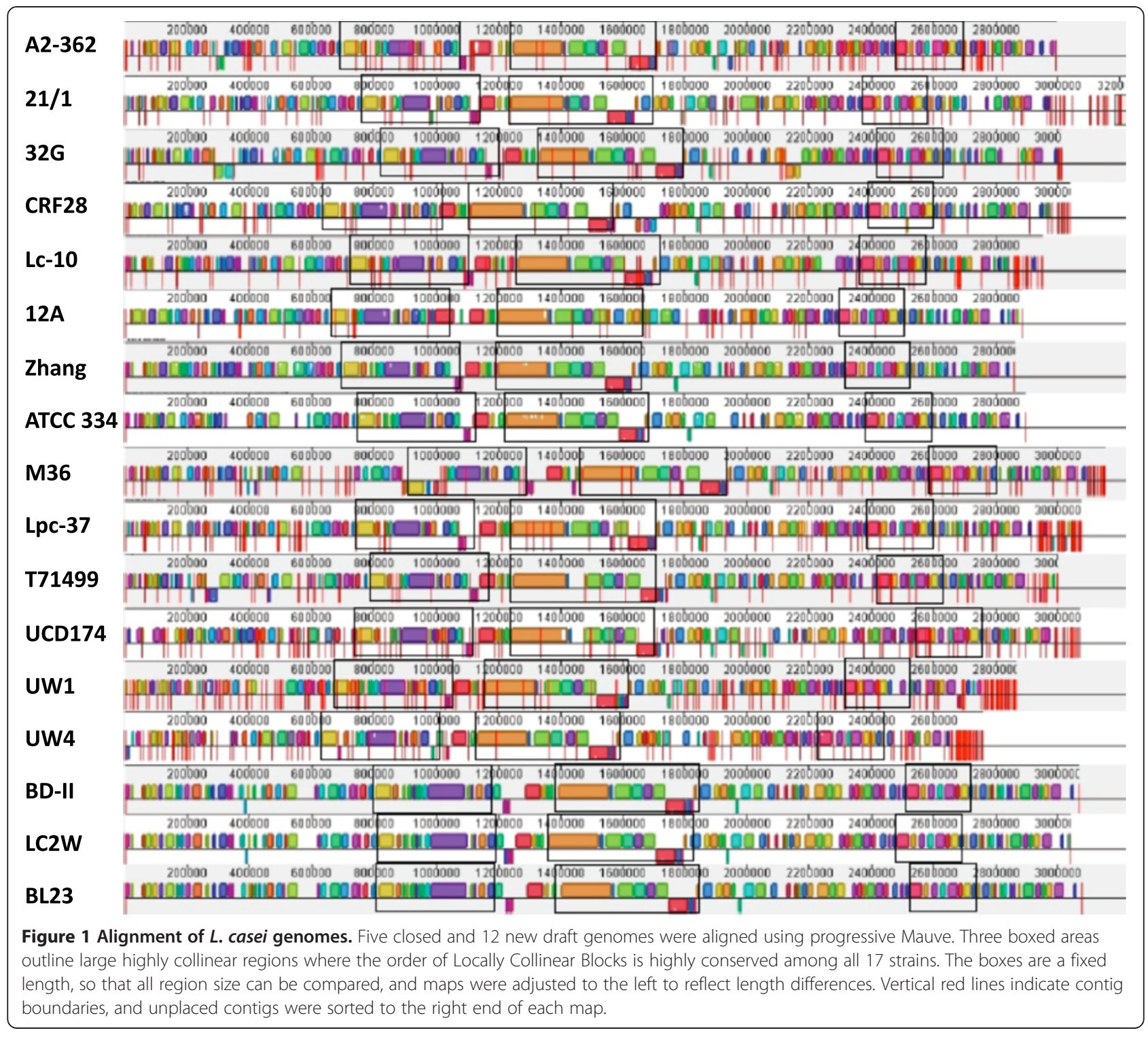

genome of 9,072 total orthologous clusters. These findings indicate $L$. case $i$ has a supragenome that is approximately 3.2 times larger than the average genome of individual strains, and support the hypothesis that the relative size and content of the pan-genome is an indicator of genetic plasticity and potential for environmental adaptation within a species [48].

\section{Strain-specific features of the $L$. casei supragenome}

Protein homology searches with strain-specific accessory gene products (i.e., unique to a particular strain) revealed $8-87 \%($ mean $=54 \%)$ of these proteins had highest similarity to gene products found in other strains of L. casei or Lactobacillus paracasei (see Additional file 2: Table S1 in the online supplementary material). The lowest fractions $(<50 \%)$ were found in the two wine isolates (A2-362 and UCD174) and three dairy strains (Lc-10, ATCC 334, and Zhang). Expansion of the analysis to include gene products with greatest homology to proteins from other species of lactobacilli accounted for 45-95\% (mean $=77 \%$ ) of the strain-specific accessory genes products. For example, different proteins with very high amino acid identity ( $E$ value $<1 \mathrm{e}^{-80}$ ) to orthologs in the closely related species Lactobacillus rhamnosus were found in all $L$. casei strains except three dairy isolates (M36, BD-II, and BL23). Additionally, strain-specific accessory genes encoding orthologs with high homology to proteins from a broad range of other Lactobacillus species including $L$. plantarum, $L$. fermentum, $L$. brevis, $L$. buchneri, $L$. coryniformis, $L$. coleohominis, L. farciminis, $L$. helveticus, L. hilgardii, L. jensenii, L. kefiranofaciens, L. ois, L. pentosus, and L. salivarius were sporadically distributed 


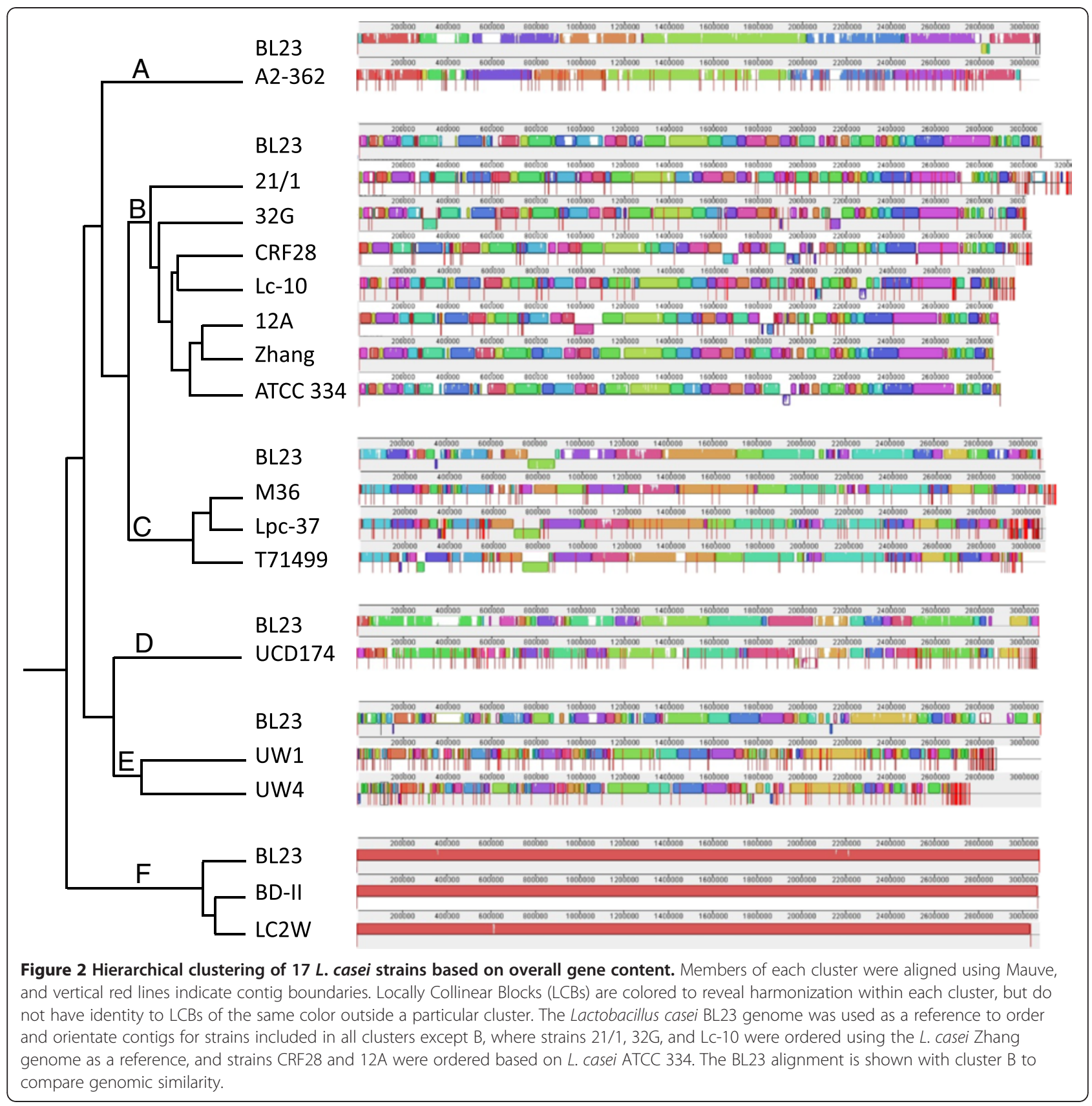

among the 17 L. casei strains examined (Additional file 2: Table S1). Many of these lactobacilli are only distantly related to $L$. casei, but all share at least one ecological niche with this species and theoretically might have contributed to the diversity of the $L$. casei supragenome. There were, for example, clear relationships between ecological co-localization with particular Lactobacillus species and the unique accessory gene content of individual L. casei strains. L. coryniformis, for example, is commonly found in fermented plant material (e.g., silage) [2] and accessory gene products with very high homology scores to various proteins from this species were found within each of the five silage and wine isolates, but not in any of the human or dairy strains (Additional file 2: Table S1). Similarly, L. casei strains of dairy origin had a greater prevalence of accessory genes whose products gave very high homology scores to different proteins from L. fermentum (Additional file 2: Table S1), a species commonly found in milk products [2].

Overall, L. casei plant isolates showed the most diverse repertoire of strain-specific accessory genes. Genes encoding orthologs with high amino acid identity to different proteins from L. plantarum, L. buchneri, and $L$. pentosus, for example, were most prevalent in plant 


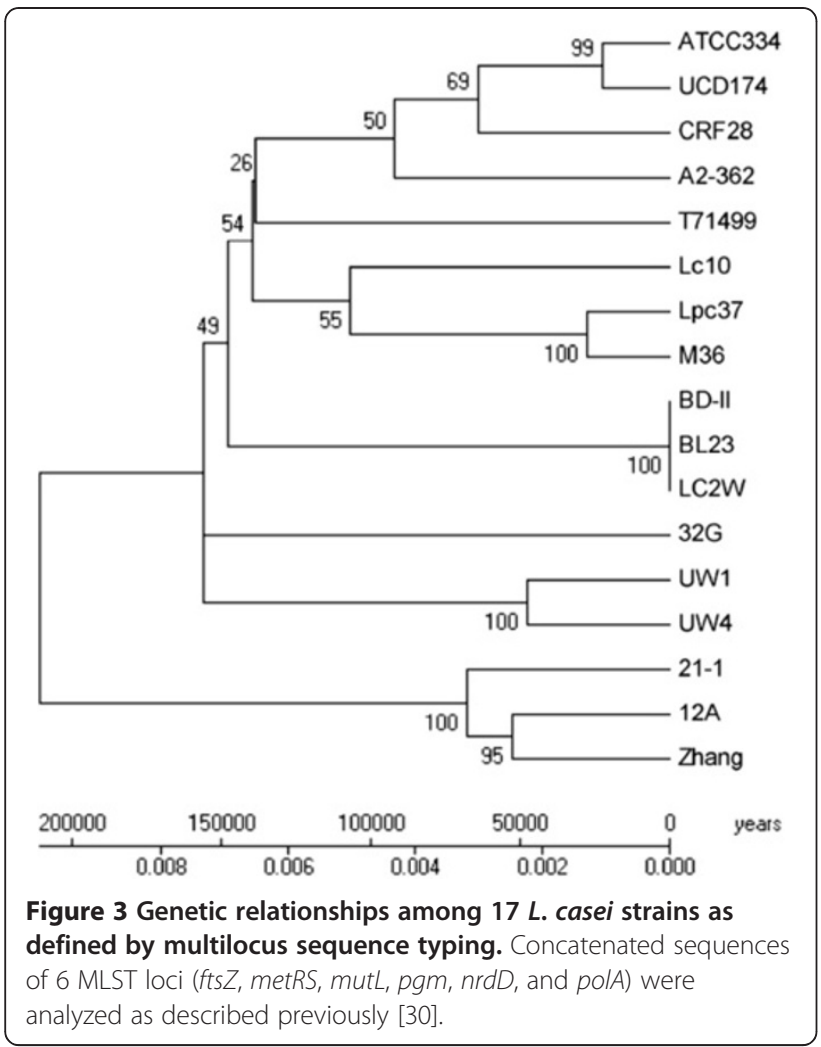

isolates, as were proteins with orthologs in distantly related bacteria such as Enterococcus, Streptococcus, Bacillus, and Clostridium species (Additional file 2: Table S1). Finally, accessory genes with very high homology scores to various proteins from Listeria sp. were detected in each of the human $L$. casei isolates and in the three dairy strains, but not in any of the plant isolates, even though Listeria are commonly recovered from vegetation [49].

If niche-associated gene exchange contributes to the composite nature of the $L$. casei supragenome, and this process is important to L. casei strain evolution and lifestyle adaptation, then one might expect to find evidence of relatively recent events among different strains. Indeed, several insertion sequence elements in $L$. casei strains shared at least $99 \%$ nucleotide sequence identity with elements that have been identified in the genomes of L. rhamnosus, L. brevis, L. buchneri, L. fermentum, Oenococcus oeni and even Listeria innocua (see Additional file 3: Table S2 in the online supplementary material). More interestingly, $L$. casei strains UCD174, BD-II, and UW1 each possess a unique polycistronic region encoding features associated with lifestyle adaptation [28] that share very high (98-99\%) nucleotide sequence identity with genomic regions in L. plantarum or L. brevis (see Additional file 3: Table S2 and Additional file 4: Figure S2 in the supplementary online material). Only one strain of L. brevis has been sequenced to date, but nucleotide BLAST searches showed each of the clusters with homology to L. plantarum was common among sequenced strains of that species.

The four-gene cluster found in L. casei UW1 is virtually identical to a locus in L. brevis ATCC 367 that encodes an $A B C$ sugar transport system of unknown specificity (Additional file 4: Figure S2A). Tests on subset of nine stains, including UW1, for the ability to grow in CDAA supplemented with one of 60 different substrates did not reveal any capability that was unique to strain UW1 (see Additional file 5: Figure S3 in supplementary online material), so the function of this gene cluster remains unclear. In both species, the cluster is flanked on one side by a gene for transposase (Additional file 4: Figure S2A), and the $\mathrm{G}+\mathrm{C}$ content of the cluster (ORFs range from 37-39\%) is considerably lower than that of either species' genome (46\%) (Table 1 and Additional file 3: Table S2), suggesting the cluster may have been acquired by one or both species from a third donor.

The polycistronic cluster identified in L. casei BD-II is plasmid borne, and carries five of the six genes that comprise the L. plantarum lar operon [50] (Additional file 4: Figure S2B). Goffin and coworkers [50] showed lar is required for lactate racemization activity in $L$. plantarum, but the function of most lar-encoded proteins, or even whether all six genes are required for this activity, remains unknown. D-lactate is a component of the cell wall in $L$. plantarum and $L$. casei, and Goffin et al. [50] suggested Lar activity may provide the cell with a rescue pathway for Dlactate production under conditions that inhibit Dlactate dehydrogenase activity. The lar genes of $L$. casei BD-II show 98-99\% nucleotide sequence identity to their counterparts in L. plantarum, and the BD-II locus is flanked on each side by transposase genes (Additional file 4: Figure S2B). There are no transposase genes in the immediate vicinity of the lar operon in L. plantarum. Collectively, these observations provide good evidence that the lar locus in $L$. casei BD-II was acquired via HGT from $L$. plantarum, but its role, if any, in lifestyle adaptation must yet be determined.

The third and most compelling example of lifestyle evolution via HGT was found in the wine isolate $L$. casei UCD174. This bacterium contains a polycistronic cluster for $\mathrm{L}(+)$-tartrate catabolism and malate transport that was previously thought to be one of three defined $L$. plantarum-specific gene clusters [51]. Tartaric and malic acids are the primary acids in grapes and therefore the strongest acids in wine. Tartrate dehydratase allows cells to convert tartrate to oxaloacetic acid, an important metabolic intermediate, and malate transport and metabolism are known to enhance acid tolerance in L. casei 


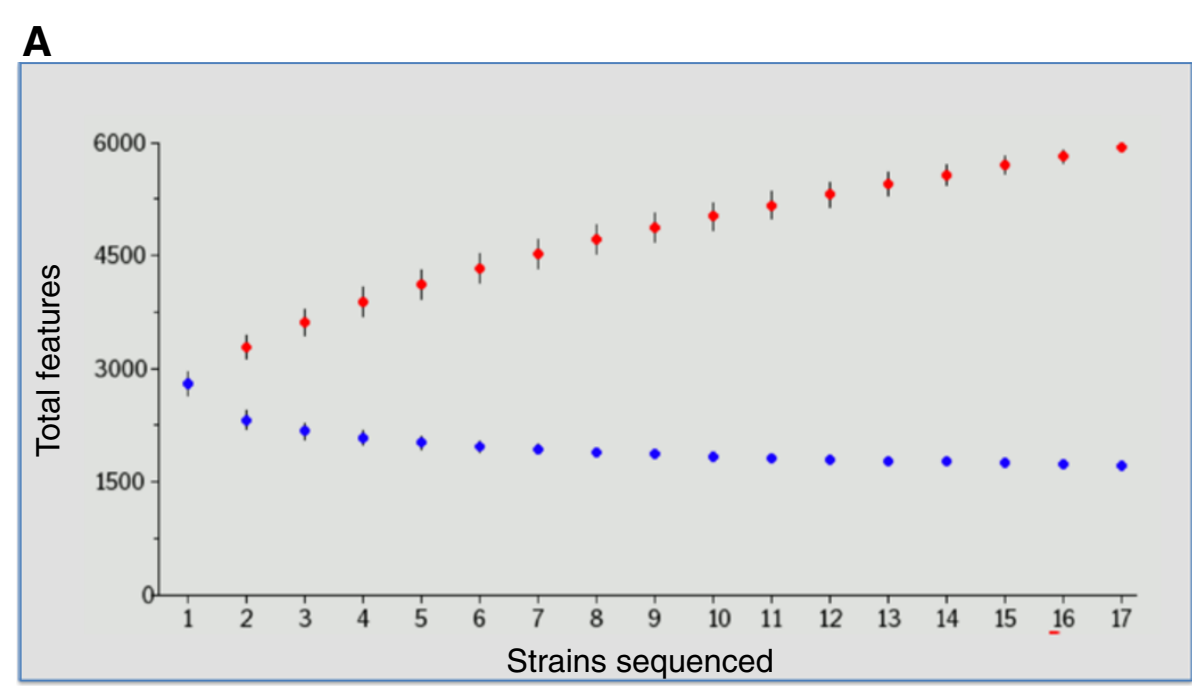

B

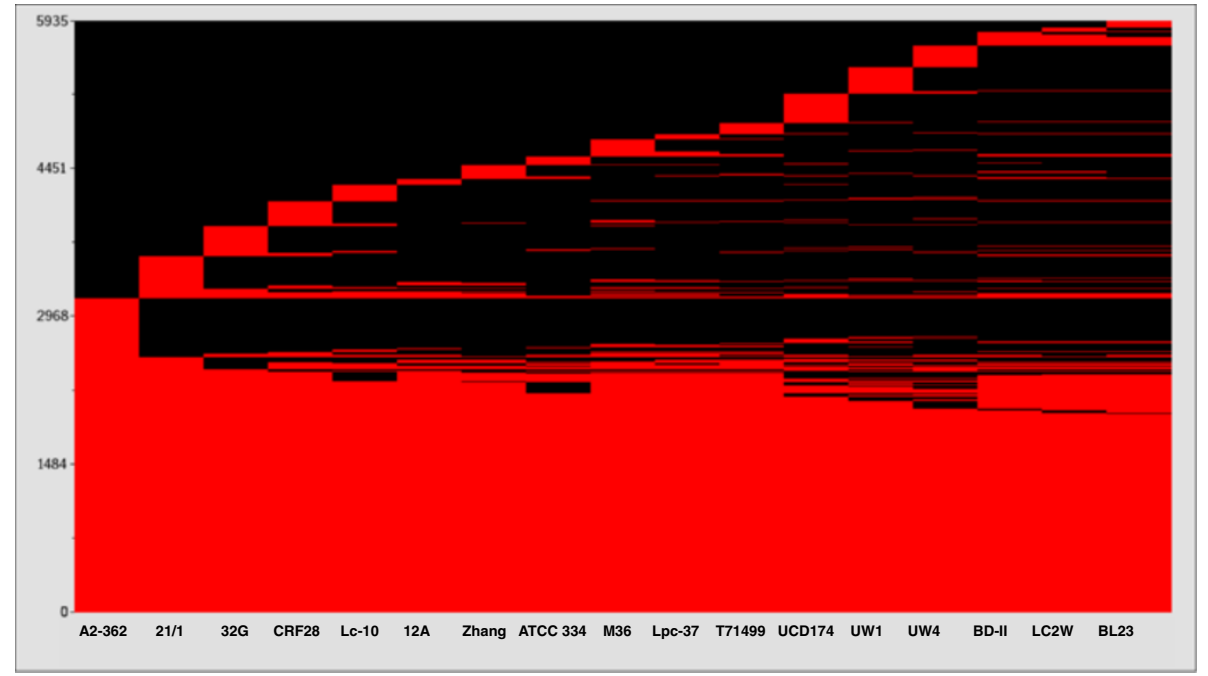

Figure 4 Feature numbers for the core and pan-genome across 17 L. casei strains. Panel $\mathbf{A}$ shows numbers of total features in the core (blue) and pan-(red) genome as a function of the number of strains sequenced. The average of 500 random permutations of the genome order is presented for the pan and core genome content; the error bars represent the standard deviation of these results. The heat map in panel $\mathbf{B}$ illustrates the distribution of core and accessory genes (combined in red) across the 17 sequenced strains. New accessory genes that are contributed to the pan-genome by each strain's sequence are depicted as a red cap at the top of each strain name. Black regions under that cap indicate features missing in that strain but present in one or more of the other sequenced L. casei.

and other lactic acid bacteria [52-54]. Thus, acquisition of this cluster by UCD174 very likely promoted survival and adaptation of this strain to the acid environment of wine. Features of the UCD174 tartrate dehydratase cluster, including $99 \%$ nucleotide sequence identity over the cluster and associated $\operatorname{aro} A B$ genes with the corresponding L. plantarum locus, and the presence of flanking transposase genes in UCD174 (Additional file 4: Figure $\mathrm{S} 2 \mathrm{C}$ ), provide strong evidence that the locus was acquired by HGT from L. plantarum.

Finally, we have noted L. rhamnosus might be an important source of genetic diversity in L. casei, but also found evidence that the reverse may be true. Of the nine publicly available complete or draft genome sequences for L. rhamnosus, only two strains, GG (ATCC 53103) and LMS2-1, contain a genomic region that encodes three secreted LPXTG-like pilin proteins (SpaCBA) plus a dedicated sortase for their export [55]. Functional genomic studies showed the SpaCBA pilus promotes adhesion to intestinal epithelial cells, and may function to modulate interleukin-8 expression that is induced by lipoteichoic acid or other surface molecules [56]. While the spaCBA locus and associated sortase are clearly uncommon among L. rhamnosus strains, it is fully conserved in L. casei strains ATCC 334, BL23, Zhang, and T71499, and present but probably inactive (due to 
frameshifts or deletions) in L. casei strains 21/1, M36, CRF28, UW4, A2-362, 32G, Lc-10, and Lpc-37. Collectively, these strains span the major MLST-defined genetic lineages for L. casei [28,30], which suggests the genes were not recently acquired. The $s p a C B A$ and sortase genes of L. casei ATCC 334 show 95-99\% nucleotide sequence identity to their counterparts in L. rhamnosus, whose locus is also flanked by transposase genes that are virtually identical to elements found in L. casei. There are no transposase genes in the immediate vicinity of the spaCBA cluster in the L. casei strains sequenced to date. Collectively, these observations provide compelling evidence that the spaCBA locus in L. rhamnosus GG and LMS2-1 may have originally been acquired via HGT from L. casei.

Overall, the composite nature of the L. casei strainspecific accessory gene pool and the presence of gene clusters in some strains that appear to have been recently acquired support our hypothesis that evolution of the L. casei supragenome has been heavily influenced by ecological co-localization with other bacterial species. Placed within the greater context of the DGH, we propose that $L$. casei, and probably other ecologically flexible species, have access to a supragenome whose composition is not exclusive to the species, but instead might be viewed as a subset of the microbial metagenome within a particular niche. While the primary mech$\operatorname{anism}(\mathrm{s})$ for supragenome access by $L$. casei are unknown, natural transformation has never been demonstrated in lactobacilli, and the prevalence of IS elements and plasmid-linked traits among genes that appear to have been recently acquired (see Additional file 3: Table S2) suggest that conjugation may be a key driver of HGT in L. casei. However, the widespread distribution of phage-related proteins among the L. casei accessory gene pool (Additional file 2: Table S1) suggest transduction could also be an important mechanism for genome evolution in this species.

\section{Adaptive immunity against invasive DNA}

Although conjugation and transduction may be important mechanisms for HGT in L. casei, these and other bacteria have also acquired sophisticated mechanisms to combat invasive bacteriophage and plasmid DNA. One key example is the CRISPR-Cas adaptive immunity system, which consists of clustered regularly interspaced short palindromic repeats (CRISPR) adjacent to cas (CRISPR-associated) genes. The CRISPR loci are comprised of partially palindromic repeats separated by short stretches of "spacer" DNA that are acquired from invasive bacteriophage or plasmid DNA. Once present, these spacer sequences allow cells to recognize and cleave invasive DNA that contains those sequences [57-60]. Two distinct types of CRISPR loci were identified in the L. casei genomes. These two loci are typically characterized by idiosyncratic CRISPR repeats: 5'-GTCTCAGGTAGATGTCGAATCA ATCAGTTCAAGAGC-3' for the Type II-A (Lsal1 family) locus, and 5'-GTTTTCCCCGCACATGCGGGGGTGAT CCC-3' for the Type I-E (Ldbu1 family) locus. Such repeats have been previously identified in a variety of lactobacilli, including L. salivarius, $L$. casei and $L$. rhamnosus for Lsal1, and L. casei, L. delbrueckii, L. fermentum, L. acidophilus and L. brevis for Ldbu1 [61]. Overall, CRISPR repeats were highly conserved, with $>97 \%$ typical repeats across Lsal1, and >96\% typical repeats for Ldbu1 (data not shown).

Lsal1-type CRISPR loci were identified in 11 strains, while Ldbu1-type loci were identified in 3 strains, with both types present in the M36 genome (Figure 5A). Only four strains (32G, A2-362, 12A, and UW4) did not possess CRISPR loci. The cas content for the Lsal1 loci is typical of Type II-A systems [62], with the universal cas 1 and cas 2 , in combination with the cas 9 signature gene. Also, a tracrRNA homologous to those found in Type II systems [63] was identified in the intergenic region between cas 9 and cas1. Though universal genes were highly conserved, up to $19 \%$ nucleotide polymorphism was observed for the cas 9 signature gene. The genomic location of these loci across the 13 strains was consistent, and occurred immediately following LCABL_23790 homologs (Figure 5A). The cas content for Ldbu1 is typical of Type I-E systems [62], with the universal cas 1 and cas 2 , in combination with the cas 3 signature gene, and Cascade-encoding genes, notably cas6e [62,64].

As expected, the spacer content was hypervariable across CRISPR loci from different strains, with spacer numbers ranging from 4 to 44 for Lsal1, and between 21 and 60 for Ldbu1 (Figure 5B). Of note, identical sets of spacers were conserved across cluster F strains (BL23, BD-II and LC2W) indicating very close genetic relatedness, which is also reflected in strain clustering based on overall gene content and MLST analysis (Figures 2 and 3). Several sets of contiguous spacers were also conserved between cluster F strains and strains Lc-10 and Zhang, which suggest common ancestry or HGT inheritance of this CRISPR locus. In contrast, spacer content showed more typical hypervariability across the other strains, with only 1 spacer shared between UW1 and UCD174 (Figure 5B). For Ldbu1, however, several sets of contiguous spacers were conserved between the dairy strains Lpc-37 and M36 (Figure 5B).

Analysis of spacer sequences revealed that numerous spacers show homology to Lactobacillus phages (Lc-Nu, A2, Lrm1, and J1) and plasmids (pYIT356, pREN, and pLgLA39) (Figure 6). Analysis of sequence conservation in the direct vicinity of proto-spacers that showed similarity or identity to CRISPR spacers revealed the presence of proto-spacer associated motifs (PAM) [65-67], 


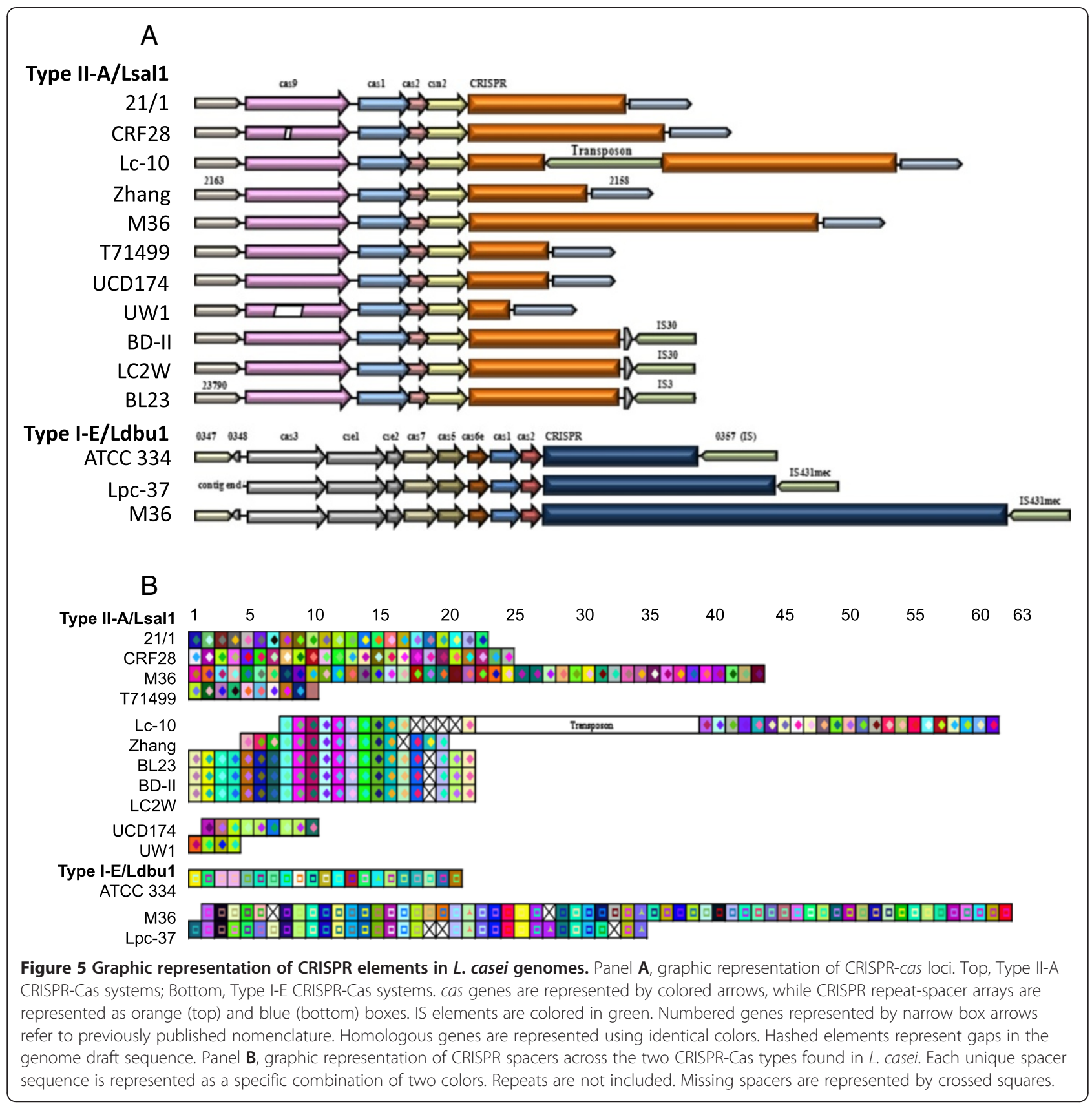

namely, a conserved TGAAA immediately downstream of the Lsal1 protospacers, and AAY immediately upstream of the Ldbu1 protospacers (Figure 6). The TGAAA pentamer is homologous to the AGAAW PAM previously identified downstream of protospacers in Streptococcus thermophilus Type II systems $[58,65,66]$.

Overall, CRISPR locus hypervariability across strains, in terms of occurrence, locus type and spacer content illustrates their functional value in response to environmental pressure, notably in providing resistance against phages. This polymorphism indicates CRISPR loci are desirable targets for typing of $L$. casei strains, in disagreement with a previous report [68]. The critical role that CRISPR-Cas systems play in resistance to viruses has been documented in dairy cultures $[57,58,65,66,69]$, as well as environmental samples [60,70-74]. The occurrence of numerous $L$. casei CRISPR spacers with homology to Lactobacillus phages (notably Lc-Nu, Lrm1, A2 and phi AT3) that prey upon closely related species (Figure 6) combined with the larger numbers of spacer sequences in strains isolated from commercial cheese production environments (Lc-10, Lpc-37 and M36) further underscores the selective pressure against phage infection that exists in industrial dairy 
manufacturing environments. The propensity of hypervariable CRISPR loci for HGT [75] is also illustrated within $L$. casei by the co-occurrence of various IS elements for both types of loci (Figure 5A), the sharing of contiguous spacer sets across strains that belong to different phylogenetic clusters (Figures 2 and 5B), and the skewed GC content of cas genes (50-63\% for Ldbu1 cas genes versus $46.5 \%$ genome-wide content). Overall, these results highlight the reliance of $L$. casei strains on CRISPR-Cas systems to provide immunity against invasive elements, as previously shown in bacteria and archaea $[57,59,60,76,77]$.

\section{Evolution via genome decay}

Our results and previous studies [21,28] have indicated HGT is a dominant force in genome evolution of $L$. casei, but a prior CGH experiment also provided evidence for a genetically distinct and geographically distributed cluster of L. casei cheese specialists whose evolution was accompanied by extensive decay of genes involved in carbohydrate utilization and transcriptional regulation [28]. This hypothesis is supported by the fact that energy production in $L$. casei is primarily derived from carbohydrate fermentation, so niche adaptation should be heavily predicated by the ability of strains to utilize available carbohydrate. Fermenting plant material, for example, can contain a diverse array of simple and complex carbohydrates as well as sugar alcohols [27], and many of these substrates will also be encountered in the GI tract as a consequence of diet. Thus, the ability to utilize C5 sugars and certain C5 and C6 sugar alcohols is more prevalent in $L$. casei isolated from plant material and the human GI tract than in cheese isolates [30]. The overlap in carbohydrate availability and use by L. casei associated with plants or the gastrointestinal tract also supports the hypothesis that many strains from these environments should be viewed as ecological generalists, whereas adaptation to cheese has been accompanied by extensive genome decay that, ultimately, resulted in niche specialization [28].

To explore the role of genome decay in the relationship between niche adaptation and substrate utilization, we tested a subset of nine stains (ATCC 334, 21/1, 32G, M36, CFR28, T71499, 12A, UW1 and UW4) distributed across the major MLST-defined $L$. casei lineages [28,30] for the ability to grow in CDAA supplemented with one of 60 different substrates associated with plant, gut, or dairy niches. Growth was detected on a total of 30 substrates, with individual strains able to utilize as few as 17 to as many as 26 different substrates (Additional file 5: Figure S3). Results showed the two cheese specialists UW1 and UW4, which share the same MLST lineage (Figure 3), had the most restricted substrate profile with growth on 18 and 17 different substrates, respectively. Each of the other strains was able to utilize at least 20 different carbohydrates, while two of the corn silage isolates (32G and 12A) each grew on 26 substrates, although their profiles were not identical (Additional file 5: Figure S3).

The genetic basis for utilization of many of these substrates is unknown, and efforts to detail the impact of genome decay on different substrate profiles is further challenged by the fact that most of $L$. casei genome sequences used for this study are incomplete. Nonetheless, 
evidence for genome decay in the evolution of the cheese specialist strains UW1 and UW4 was observed in regard to genes for inulin, sucrose and cellobiose utilization. In $L$. casei, the ability to ferment sucrose and inulin is encoded by an operon for fructooligosaccharide utilization (fos) $[78,79]$ that is present in the other seven strains tested, which were all sucrose- and inulin-positive, but completely absent in UW1 and UW4.

In contrast to the single fos operon, we identified nine distinct gene clusters among the $17 \mathrm{~L}$. casei genomes studied here that may function in cellobiose utilization (Figure 7). Cellobiose is a disaccharide formed by enzymatic or acid hydrolysis of cellulose that, like sucrose and inulin, may be encountered in plant material or in the human gastrointestinal tract but not in milk or cheese. Each of the nine strains analyzed in this part of the study possessed single copies of one (UW1) to eight (21/1 and 12A) of these gene clusters (Figure 7), and all but UW1 were able to ferment cellobiose (Additional file 5: Figure S3). While the function of each cluster in cellobiose utilization (as opposed to other $\beta$-glucosides) has not been demonstrated, data for strains ATCC 334 and UW4 show at least two of these clusters must enable cellobiose fermentation in L. casei (Figures 7 and S3). Cross comparison of the distribution of clusters 1 to 6 across the MLST lineages for the nine L. casei strains tested (Figures 3 and 7) provides clear evidence of genome decay; many clusters are entirely absent, presumably due to deletion events, and all but $12 \mathrm{~A}$ contained at least one cluster that was predicted to be nonfunctional due to frameshift mutations (Figure 7). The single cluster in the cellobiose-negative strain UW1, for example, was predicted to be nonfunctional (Figure 7). Finally, examination of all 17 genomes included in this study confirmed the cheese specialists UW1 and UW4 had the fewest total cellobiose clusters, and were the only strains lacking cluster 5 .

\section{Conclusions}

In bacteria, the concept of species is traditionally anchored to features that are encoded by the core genome, but which often do not adequately describe the genetic diversity that is characteristic of a particular species $[22,80]$. Thus, there is increasing awareness that a large number of strains, preferably of disparate origin, must be sequenced to gain an accurate understanding of

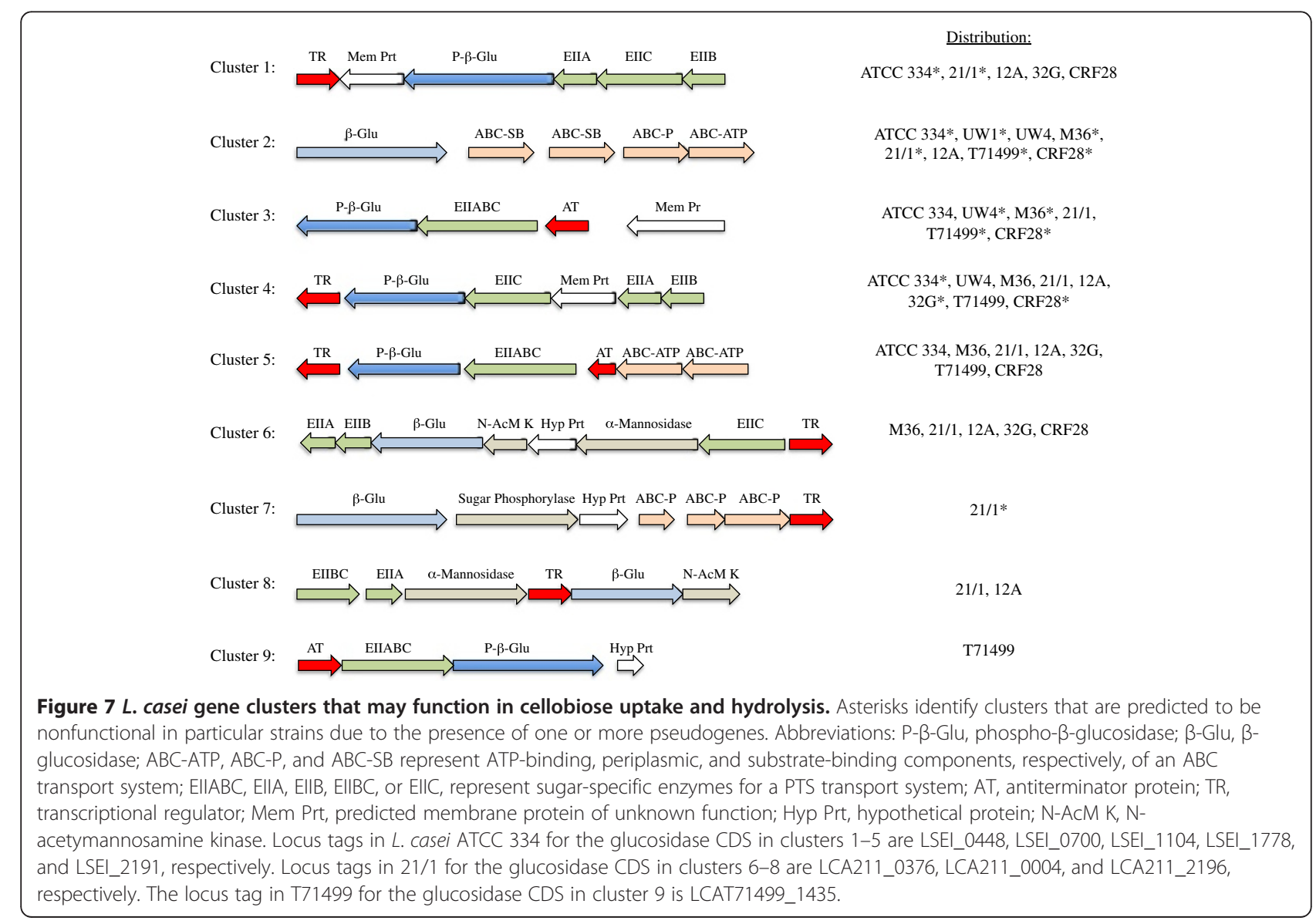


the evolution and biology of a particular bacterial species. To our knowledge, this is the first study to explore genome evolution and diversity in an ecologically flexible lactic acid bacterium using genome sequences from a large number of ecologically divergent strains.

As is depicted in Figure 4, the $17 \mathrm{~L}$. casei genomes included in the study were not sufficient to capture the full pan-genome of this remarkable species. Indeed, mathematical extrapolation of these data indicated only $2 / 3$ of the actual $L$. casei pan-genome has been sequenced to date (5,935 orthologous clusters found versus an estimated 9,072 total). Evidence for a much larger, open pan-genome was also provided by hierarchical clustering of strains based on overall gene content, since 2 of the 6 clusters (A and D) currently contain single isolates. Overall, our findings indicate $L$. casei has an open and distributed supragenome that is approximately 3.2 times larger than the average genome size for individual strains.

Characterization of the L. casei supragenome suggested its composition has been influenced by ecological co-localization with other bacterial species, especially lactobacilli. These findings provide additional confirmation that the DGH extends to non-pathogenic species [42], and indicate ecologically flexible bacteria like $L$. casei have access to a supragenome whose composition might be viewed as a subset of the microbial metagenome within a particular ecological niche. Finally, our results also provide support for the hypothesis that HGT has been a dominant force in adaptation of $L$. casei to new habitats and lifestyles, and that evolution of a genetically distinct and geographically distributed cluster of $L$. casei cheese specialists has been accompanied by extensive decay of genes associated with carbohydrate utilization [28].

\section{Methods}

\section{Genome sequencing and assembly}

Genomic DNA was extracted using a MasterPure GramPositive DNA Purification Kit (Epicentre Biotechnologies, Madison, WI). All 12 of the genome drafts were sequenced using a whole-genome shotgun strategy by pyrosequencing (GS FLX Titaninum 454 Life Sciences). The Lpc-37 and Lc-10 genomes were sequenced by University of Illinois-Urbana Champaign under contract services. The remaining 10 genomes were sequenced as a contract service by the Génome Québec Innovation Centre at McGill University (Montreal, Canada). Resulting sequences were assembled de novo using NGen SeqMan 2.0 (DNAstar, Madison, WI). The draft contigs for each genome assembly were compared to all five published genomes (Table 1) using progressive Mauve genome alignment software [81] and visually inspected for the best overall matching Local Collinear Blocks (LCBs).
Based on the best matches, each draft was individually ordered and contigs oriented, but unlocated contigs were not scaffolded. Using the new contig orientation and order, the drafts assemblies were improved by hand curation in silico using SeqMan 8.1.2 (DNAstar). For strain Lpc-37, the draft genome assembly was also validated by comparison to a NheI optical restriction map (OpGen Inc, Gaithersburg MD) (see Additional file 1: Figure S1 in supplementary online material).

Initial annotations were generated using the RAST annotation server (http://rast.nmpdr.org/) with subsequent manual inspection and curation, including comparative analyses to improve consistency among orthologous groups. Pseudogene assignments were not exhaustive and were based on the available sequence; they may be influenced by sequencing artifacts due to the draft nature of the genomes.

\section{Ortholog predictions}

Ortholog predictions were made based on reciprocalbest Basic Local Alignment Search Tool (BLAST; http:// blast.ncbi.nlm.nih.gov/Blast.cgi) hits using a cutoff of $80 \%$ identity over $80 \%$ of the length. Confirmation of the reciprocal BLAST data and additional ortholog predictions were generated from whole-genome Mauve alignment data using a custom script and the A Systematic Annotation Package (ASAP) for Community Analysis of Genomes database (https://asap.ahabs.wisc.edu) [82]. This script uses synteny to determine whether features should be confirmed as orthologs, and can add orthologs based on genome context in cases where the BLAST results are ambiguous (e.g. paralogs) or that fail the cutoffs. This allows the initial BLAST assessment to be more strict, preventing the inclusion of homologs in the ortholog table and providing a one-to-one ortholog relationship between genomes.

\section{CDS and MLST dendrograms}

A present/absent matrix of the CDS in all 17 strains of L. casei was created by a custom script and used to generate a dendrogram by the Ward method of hierarchical clustering (JMP version 9). Multiple sequence alignments were performed using molecular evolutionary genetic analysis (MEGA) software version 4 (http:// www.megasoftware.net). A minimum evolution (ME) tree for all $17 \mathrm{~L}$. casei strains was constructed using MEGA 4 based on the results of a bootstrapping test (1000 replicates) of strain phylogeny [83]. The phylogenetic tree was linearized assuming equal evolutionary rates in all lineages [84]. The evolutionary distances were computed using the modified Nei-Gojobori method [85] and are presented in the units of the number of synonymous substitutions per synonymous site. All positions containing gaps and missing data 
were eliminated from the dataset (complete deletion option).

To estimate the divergence time among different $L$. casei clusters, the concatenated sequences of 6 MLST loci (ftsZ, metRS, mutL, pgm, nrdD, and polA) were analyzed as described previously [30]. Divergence times between different clusters were indicated in a scale of millions of years. Calculations were based on the number of single nucleotide substitutions in each strain, and the estimated rate of single nucleotide substitutions between Escherichia coli and Salmonella enterica of $4.7 \times$ $10^{-9}$ per site per year $[86,87]$.

\section{Estimation of the $L$. casei core and pan-genome size}

Protein coding features in each genome were grouped using OrthoMCL [88] with default settings and the resulting data were uploaded to the ASAP database. These data were retrieved from the database with a custom script that organized the feature IDs into a tabdelimited matrix allowing for identification of accessory genes (all features not included in the core genome) and strain-specific genes (unique to a single isolate) by inspection of this table. The best hits of the strain-specific features from a BLAST [89] analysis against the nr database using default parameters were collected and are presented in Additional file 2: Table S1. Graphical depictions of $L$. casei pan and core genome data, including the heat map, were generated using a custom php-based script that polls these data from the ASAP database and builds a present/absent matrix. Pan and core genome size estimates were derived with an R-package using a binomial mixture model [48].

\section{CRISPR identification and characterization}

CRISPR loci were identified using a combination of homology to previously indentified repeats [61], de novo identification using CRISPRFinder [90] and repeat region identification using Dotter [91]. Spacers were visualized as previously described [66], and homologies to foreign genetic elements were assessed using BLAST [92]. CRISPR loci sequences were independently confirmed by Sanger sequencing of PCR amplicons. Nucleotide conservation between CRISPR spacers and corresponding proto-spacers in phages, plasmids and chromosomal sequences were visualized using WebLogo [93].

\section{Carbohydrate utilization}

L. casei strains 21/1, 12A, M36, UCD174, A2-362, 32G, T71499, CRF28, UW1, UW4, and ATCC 334 were transferred from $-80 \mathrm{C}$ freezer stocks into MRS broth (Difco Laboratories, Detroit, MI) and grown overnight (16-18 h) at $37^{\circ} \mathrm{C}$. Strains were inoculated at $1 \%(\mathrm{v} / \mathrm{v})$ into a filtersterilized chemically defined amino acid medium (CDAA) with $25 \mathrm{mM}$ galactose and incubated $16-18 \mathrm{~h}$ at $37^{\circ} \mathrm{C}$.
The CDAA was comprised of $114 \mathrm{mg}$ sodium acetate, $171 \mathrm{mg}$ sodium citrate, $171 \mathrm{mg}$ ammonium chloride, $343 \mathrm{mg}$ potassium phosphate (monobasic), $343 \mathrm{mg}$ potassium phosphate (dibasic), $114 \mathrm{mg}$ magnesium sulfate tetrahydrate, $6 \mathrm{mg}$ iron sulfate hexahydrate, $6 \mathrm{mg}$ manganese sulfate tetrahydrate, $4 \mathrm{~g}$ sodium chloride, $228 \mathrm{mg}$ L-phenylalanine, $455 \mathrm{mg}$ L-tyrosine, $6 \mathrm{mg}$ L-adenine, 6 $\mathrm{mg}$ L-guanine, $6 \mathrm{mg}$ L-uracil, $6 \mathrm{mg}$ L-xanthine, $351 \mathrm{mg}$ DL-aspartate, $245 \mathrm{mg}$ L-glutamate, $545 \mathrm{mg}$ L-tryptophan, $443 \mathrm{mg}$ L-alanine, $312 \mathrm{mg} \mathrm{L}$-arginine, $746 \mathrm{mg} \mathrm{L}-$ asparagine, $857 \mathrm{mg}$ L-cysteine, $816 \mathrm{mg}$ L-glutamine, 341 mg glycine, $900 \mathrm{mg}$ L-histidine, $923 \mathrm{mg}$ L-isoleucine, $326 \mathrm{mg}$ L-leucine, $428 \mathrm{mg}$ L-lysine, $148 \mathrm{mg}$ DL-methionine, $93 \mathrm{mg}$ L-proline, $946 \mathrm{mg}$ DL-serine, $404 \mathrm{mg}$ DLthreonine, $651 \mathrm{mg}$ L-valine, $24 \mathrm{mg}$ L-cystine, $1 \mathrm{~mL}$ trace elements solution [94], $0.4 \mathrm{~mL}$ Tween $80,0.4 \mathrm{~mL}$ Tween 20, $0.4 \mathrm{~mL}$ Tween 60, plus $10 \mathrm{~mL}$ RPMI 1640 vitamin solution (100X; added prior to experimentation), and $\mathrm{pH}$ adjusted to 5.5 .

Cells were collected by centrifugation at $13,000 \mathrm{x} g$ for 5 min at $4^{\circ} \mathrm{C}$, then suspended in CDAA lacking carbohydrate. Samples of each strain were then added to a final absorbance at $595 \mathrm{~nm}\left(\mathrm{~A}_{595}\right)$ of 0.1 into $1 \mathrm{~mL}$ CDAA adjusted to $\mathrm{pH} 5.5$ that contained $2 \mathrm{mM}$ galactose as a growth booster plus one of the following substrates: 25 $\mathrm{mM}$ meso-erythritol, D-xylose, D-ribose, D-arabinose, Dadonitol, D-arabitol, D-xylitol, D-glucose, D-mannose, D-galactose, D-fructose, lactone, D-mannitol, D-galactitol, D-sorbitol, myo-inositol, D-glucosamine, n-acetyl Dglucosamine, sialic acid (Indofine Chemical Company, Inc., Hillsborough, NJ), lactulose, D-lactose, D-sucrose, D-turanose, D-maltose, D-cellobiose, D-trehalose, Dmaltitol, D-lactitol, D-raffinose, or D-melezitose; or 4.5 $\mathrm{mg} / \mathrm{mL}$ (which is equivalent to $25 \mathrm{mM}$ glucose) of heparin, $\mathrm{N}$-acetyl-D-galactosamine, fucose, panose, galactosamine, amylopectin, high methylated pectin, stachyose, pectin, arabinogalactan, rhamnose, inulin, mucin, or phytic acid; or $12.5 \mathrm{mg} / \mathrm{mL}$ isomaltose, galacturonic acid, polydextrose, glucuronic acid, amygdalin, maltotriose, pullulan, amylopectin, carboxymethyl cellulose, xylan, lignin, $\alpha$-cyclodextrin, $\beta$-cyclodextrin, $\gamma$-cyclodextrin, dextrin, or amylose. Unless noted, substrates were purchased from Sigma-Aldrich Co. (St. Louis, MO). Strains A2-362 and UCD174 were not included in these studies because they were unable to grow well in CDAA.

Inoculated mixtures were incubated at $37^{\circ} \mathrm{C}$ under static conditions. Aliquots $(50 \mu \mathrm{l})$ were periodically collected over a $48 \mathrm{~h}$ period, placed in a 96-well microtiter plate, and $A_{595}$ was determined using a 96 well platereader (Bio-Rad, Hercules, CA). Uninnoculated mixtures containing individual substrates were used as blanks for the plate reader. Carbohydrates that produced a turbid sample at time 0 (amylopectin, mucin, carboxymethyl cellulose, xylan, lignin, $\alpha$-cyclodextrin, $\gamma$-cyclodextrin, 
$\beta$-cyclodextrin, dextrin, and amylose) were diluted in a $0.9 \%$ sterile saline solution and plated on MRS agar (Difco Laboratories) using the drop plate method [95]. Plates were incubated at $37^{\circ} \mathrm{C}$ for $48 \mathrm{~h}$ prior to colony enumeration.

All growth experiments were performed in triplicate, and the ability to utilize a particular substrate was determined by two-tailed student's t-test comparison $(\alpha=$ 0.05) between the mean $A_{595}$ values from cells incubated in CDAA containing no carbohydrate versus CDAA containing the substrate of interest. A dendrogram showing the relationships between strains in regard to substrate utilization was created using the Ward method in hierarchical clustering (JMP version 9, SAS Institute Inc., Cary, NC).

\section{Identification of cellobiose gene clusters}

Putative gene clusters for cellobiose utilization were identified by keyword screening of gene annotations for " $\beta$-glucosidase", and by BLAST homology searches of each genome using $\beta$-glucosidase protein sequences from the Carbohydrate-Active enZYmes database (www. cazy.org). Neighboring genes were then examined for support functions such as cellobiose transport and transcription activators or terminators.

\section{Additional files}

Additional file 1: Figure S1. Comparative analysis of the L. casei Lpc-37 chromosome Optical Map with its in silico equivalent. Shown are: (a) in silico Optical Map contigs were ordered in an alternating pattern to demonstrate the boundaries of the current ordered draft, without unplaced contigs; (b) The Nhel Optical Map of Lpc-37 used as a reference to independently validate the assembly and order of the contig draft. Orange shaded regions indicate where alignment match more than once and blue regions indicate a single alignment match. Green boxes highlight the regions that have no coverage in the ordered draft. Site 1 is approximately $30 \mathrm{~kb}$, site 2 is approximately $70 \mathrm{~kb}$ and site 3 is approximately $10 \mathrm{~kb}$. Part (c) depicts the concatenated sequence of the ordered contigs in the draft of Lpc-37, without the unplaced contigs; and (d) shows the remaining unplaced contigs were very small and could not be ordered based on Optical Map alignment.

Additional file 2: Table S1. Protein homology data for predicted strainspecific accessory gene products in $L$. casei strains.

Additional file 3: Table S2. Evidence for recent intraspecific and nicheassociated horizontal gene transfer in L. casei.

Additional file 4: Figure S2. Polycistronic clusters that may reflect recent intraspecific and niche-associated horizontal gene transfer in $L$. casei. Panel A, graphic representation of an ABC sugar transport system found in L. casei UW1 and L. brevis ATCC 367. Abbreviations: lacL $=\beta$ galactosidase large subunit; lacM = $\beta$-galactosidase small subunit; LVIS_2257 = ABC-type sugar transport system, ATPase component; LVIS_2256 = multiple sugar ABC transporter, substrate-binding protein; LVIS_2254 and LVIS_2255 = multiple sugar ABC transporter, membranespanning permease protein; LVIS_2252 = oxidoreductase; reg = transcriptional regulator; hyp $=$ hypothetical protein; $t n=$ transposase. Panel B, graphic representation of the plasmid-coded partial lar operon present in L. casei BD-II and its alignment with a corresponding region of the $L$. plantarum genome. Abbreviations: $c b i M=$ cobalt $A B C$ transporter, substrate-binding protein; Ip_0103 = transcriptional regulator; larA = phosphoribosylcarboxy-aminoimidazole (NCAIR) mutase; larB = unknown function; $\operatorname{lar} C 1$ and $\operatorname{lar} C 2=$ unknown function; $g \mid p F 1=$ glycerol uptake facilitator protein; larE = unknown function; Ip_0111 = quinone oxidoreductase; thi $M=$ hydroxyethylthiazole kinase. Panel $C$, graphic representation of the tartrate dehydratase operon and flanking genes found in L. casei UCD174 and their alignment with a corresponding region in the L. plantarum genome. Abbreviations: $m t s A=$ manganese transport system, ATP binding protein; citG = 2'-(5"-triphosphoribosyl)-3dephospho-CoA synthase; $t t d R=$ transcription regulator tartrate operon; $t t d A=$ tartrate dehydratase a subunit; $t t d B=$ tartrate dehydratase $\beta$ subunit; $t t d P=2$-oxoglutarate /malate translocator protein; $\operatorname{aro} B=3$ dehydroquinate synthetase; $\operatorname{aro} A=3$-deoxy-7-phosphoheptulonase synthase; $\operatorname{aroD} 1$ = shikimate 5 -dehydrogenase; $t k t 2=$ transketolase. Vertical lines in each panel denote the region that displays $98-99 \%$ nucleotide sequence identity between each paired comparison (see text).

Additional file 5: Figure S3. Variable growth among nine L. casei strains on selected substrates. Blue indicates growth and yellow indicates negligible growth within 48 hours. Hierarchical clustering of strains based on substrate utilization profile is also depicted. Carbohydrates which were utilized for growth by all strains tested include D-glucose (shown), as well as D-mannose, D-galactose, D-fructose, D-mannitol, Dturanose, and D-melezitose galactosamine (not depicted). Growth was not observed with meso-erythritol, D-arabinose, D-adonitol, D-arabitol, Dxylitol, D-galactitol, myo-inositol, sialic acid, heparin, fucose, amylopectin, rhamnosemucin, phytic acid, galacturonic acid, glucuronic acid, amylopectin, carboxymethyl cellulose, xylan, lignin, a-cyclodextrin, $\beta$ cyclodextrin, $\gamma$-cyclodextrin, dextrin, and amylose.

\section{Abbreviations}

BLAST: Basic local alignment search tool; CDS: Coding sequence; CGH: Comparative genome hybridization; CRISPR: Clustered regularly interspaced short palindromic repeats; DGH: Distributed genome hypothesis; HGT: Horizontal gene transfer; LCB: Locally collinear blocks; MLST: Multi-locus sequence typing; OD: Optical density; PAM: Proto-spacer associated motifs.

\section{Competing interests}

$\mathrm{BS}, \mathrm{WM}, \mathrm{PH}, \mathrm{RB}$, and JLS received salary and/or funding from DuPont, a supplier of bacterial cultures to the food industry. Peggy Steele, a member of JLS's family, is also employed by DuPont.

\section{Authors' contributions}

$J R B, J L S, R B, B S, E C N-E, N P, H C$, and PH conceived and designed the study; $J R B, E C N-E, B S, K T, J H, W M$, and RB performed experiments and bioinformatic analyses; JRB, JLS, KT, JH, ECN-E, HC, RB, BS, NP, and WM contributed to data interpretation; $\mathrm{PH}$ contributed reagents, materials and analytical/technical expertise; JRB, JLS, ECN-E, RB, and BS wrote the paper. All authors read and approved the final manuscript.

\section{Acknowledgements}

We thank Anne-Claire Coûté-Monvoisin for technical assistance and Lars Snipen for providing a pre-release version of his R-package software. This work was supported by Danisco, Inc., the United States Department of Agriculture, the U.S. Department of Energy Great Lakes Bioenergy Research Center (DOE BER Office of Science DE-FC02-07ER64494), and the Utah Agricultural Experiment Station (UAES). This manuscript was approved by the UAES as journal paper number 8424 .

\section{Author details}

'Utah State University Department of Nutrition, Dietetics, and Food Sciences, 8700 Old Main Hill, Logan, UT 84322-8700, USA. ${ }^{2}$ University of Wisconsin Biotechnology Center, 425 Henry Mall, Madison, WI 53706-1580, USA. ${ }^{3}$ DuPont Nutrition and Health, 3329 Agriculture Drive, Madison, WI 53716, USA. ${ }^{4}$ University of Wisconsin Department of Food Science, 1605 Linden Drive, Madison, WI 53706-1565, USA. ${ }^{5}$ Present address: PPD Inc, 466 Devon Park Dr, Wayne, PA 19087, USA. 'DuPont Nutrition and Health, BP10, F-86220, Dangé-Saint-Romain, France. ${ }^{7}$ University of Wisconsin Laboratory of Genetics, 425 Henry Mall, Madison, WI 53706-1580, USA.

Received: 3 April 2012 Accepted: 27 September 2012 Published: 5 October 2012 


\section{References}

1. Axelsson L: Lactic acid bacteria: classification and physiology. In Lactic acid bacteria microbiological and functional aspects. 3rd edition. Edited by Salminen S, von Wright A, Ouwehand A. New York: Marcel Dekker Inc; 2004:1-66.

2. Kandler O, Weiss N: Genus Lactobacillus. In Bergey's manual of systematic bacteriology. 9th edition. Edited by Sneath PHA, Mair NS, Sharpe ME, Holt JG. Baltimore: Williams and Wilkins; 1986:1063-1065.

3. Beresford T, Williams A: The microbiology of cheese ripening. In Cheese: Chemistry, Physics and Microbiology. 3rd edition. Edited by Fox PF, McSweeney PLH, Cogan TM, Guinee TP. Amsterdam, the Netherlands: Elsevier; 2004:287-318

4. Judicial Commission of the International Committee on Systematics of Bacteria: The type strain of Lactobacillus casei is ATCC 393, ATCC 334 cannot serve as the type because it represents a different taxon, the name Lactobacillus paracasei and its subspecies names are not rejected and the revival of the name 'Lactobacillus zeae' contravenes Rules 51b (1) and (2) of the International Code of Nomenclature of Bacteria. Opinion 82. Int J Syst Evol Microbiol 2008, 58:1764-1765.

5. Goldin BR, Gorbach SL: Probiotics for humans. In Probiotics: the scientific basis. Edited by Fuller R. London: Chapman and Hall; 1992:355-376.

6. Stiles ME, Holzapfel WH: Lactic acid bacteria of foods and their current taxonomy. Int J Food Microbiol 1997, 36:1-29.

7. Mayra-Makinen A, Bigret M: Industrial use and production of lactic acid bacteria. In Lactic acid bacteria-microbiology and functional aspects. 2nd edition. Edited by Salminen S, Wright AV. New York: Marcel Dekker Inc: 1998:73-102.

8. FAO/WHO: Health and nutritional properties of probiotics in food including powder milk with live lactic acid bacteria. In Report of a joint FAO/WHO expert consultation. London: FAO; 2001

9. Sokurenko EV, Chesnokova V, Dykhuizen DE, Ofek I, Wu XR, Krogfelt KA, Struve C, Schembri MA, Hasty DL: Pathogenic adaptation of Escherichia coli by natural variation of the FimH adhesin. Proc Natl Acad Sci USA 1998, 95:8922-8926

10. Giraud A, Matic I, Tenaillon O, Clara A, Radman M, Fons M, Taddei F: Costs and benefits of high mutation rates: Adaptive evolution of bacteria in the mouse gut. Science 2001, 291:2606-2608.

11. Tenaillon O, Taddei F, Radmian M, Matic I: Second-order selection in bacterial evolution: selection acting on mutation and recombination rates in the course of adaptation. Res Microbiol 2001, 152:11-16.

12. Feldgarden M, Byrd N, Cohan FM: Gradual evolution in bacteria: evidence from Bacillus systematics. Microbiol 2003, 149:3565-3573.

13. Lawrence JG: Gene transfer, speciation, and the evolution of bacterial genomes. Curr Opin Microbiol 1999, 2:519-523.

14. De Koning AP, Brinkman FS, Jones SJ, Keeling PJ: Lateral gene transfer and metabolic adaptation in the human parasite Trichomonas vaginalis. Mol Biol Evol 2000, 17:1769-1773.

15. Ochman H, Lawrence JG, Groisman EA: Lateral gene transfer and the nature of bacterial innovation. Nature 2000, 405:299-304.

16. McLysaght A, Baldi PF, Gaut BS: Extensive gene gain associated with adaptive evolution of poxviruses. Proc Natl Acad Sci USA 2003, 100:15655-15660.

17. Springael D, Top EM: Horizontal gene transfer and microbial adaptation to xenobiotics: new types of mobile genetic elements and lessons from ecological studies. Trends Microbiol 2004, 12:53-58.

18. Cole ST, Eiglmeier K, Parkhill J, James KD, Thomson NR, Wheeler PR, Honoré N, Garnier T, Churcher C, Harris D, Mungall K, Basham D, Brown D, Chillingworth T, Connor R, Davies RM, Devlin K, Duthoy S, Feltwell T, Fraser A, Hamlin N, Holroyd S, Hornsby T, Jagels K, Lacroix C, Maclean J, Moule S, Murphy L, Oliver K, Quail MA, Rajandream MA, Rutherford KM, Rutter S, Seeger K, Simon S, Simmonds M, Skelton J, Squares R, Squares S, Stevens K, Taylor K, Whitehead S, Woodward JR, Barrell BG: Massive gene decay in the leprosy bacillus. Nature 2001, 409:1007-1011.

19. Ogata H, Audic S, Renesto-Audiffren P, Fournier PE, Barbe V, Samson D, Roux V, Cossart P, Weissenbach J, Claverie JM, Raoult D: Mechanisms of evolution in Rickettsia conorii and R. prowazekii. Science 2001, 293:2093-2098.

20. Mirkin BG, Fenner TI, Galperin MY, Koonin EV: Algorithms for computing parsimonious evolutionary scenarios for genome evolution, the last universal common ancestor and dominance of horizontal gene transfer in the evolution of prokaryotes. BMC Evol Biol 2003, 3:e2.

21. Makarova K, Slesarev A, Wolf Y, Sorokin A, Mirkin B, Koonin E, Pavlov A, Pavlova N, Karamychev V, Polouchine N, Shakhova V, Grigoriev I, Lou Y Rohksar D, Lucas S, Huang K, Goodstein DM, Hawkins T, Plengvidhya V,
Welker D, Hughes J, Goh Y, Benson A, Baldwin K, Lee JH, Díaz-Muñiz I, Dosti B, Smeianov V, Wechter W, Barabote R, Lorca G, Altermann E, Barrangou R, Ganesan B, Xie Y, Rawsthorne H, Tamir D, Parker C, Breidt F, Broadbent J, Hutkins R, O'Sullivan D, Steele J, Unlu G, Saier M, Klaenhammer T, Richardson P, Kozyavkin S, Weimer B, Mills D: Comparative genomics of the lactic acid bacteria. Proc Natl Acad Sci USA 2006, 103:15611-15616.

22. Tettelin H, Masignani V, Cieslewicz MJ, Donati C, Medini D, Ward NL, Angiuoli SV, Crabtree J, Jones AL, Durkin AS, Deboy RT, Davidsen TM, Mora M, Scarselli M, Margarit y Ros I, Peterson JD, Hauser CR, Sundaram JP, Nelson WC, Madupu R, Brinkac LM, Dodson RJ, Rosovitz MJ, Sullivan SA, Daugherty SC, Haft DH, Selengut J, Gwinn ML, Zhou L, Zafar N, et al: Genome analysis of multiple pathogenic isolates of Streptococcus agalactiae: Implications for the microbial "pan-genome". Proc Natl Acad Sci USA 2005, 102:13950-13955.

23. Marri PR, Hao W, Golding GB: Gene gain and gene loss in streptococcus: is it driven by habitat? Mol Biol Evol 2006, 23:2379-2391.

24. Berger B, Pridmore RD, Barretto C, Delmas-Julien F, Schreiber K, Arigoni F, Brüssow H: Similarity and differences in the Lactobacillus acidophilus group identified by polyphasic analysis and comparative genomics. J Bacteriol 2007, 189:1311-1321.

25. Hiller NL, Janto B, Hogg JS, Boissy R, Y U S, Powell E, Keefe R, Ehrlich NE, Shen K, Hayes J, Barbadora K, Klimke W, Dernovoy D, Tatusova T, Parkhill J, Bentley SD, Post JC, Ehrlich GD, Hu FZ: Comparative genomic analyses of seventeen Streptococcus pneumoniae strains: insights into the pneumococcal supragenome. J Bacterio/ 2007, 189:8186-8195.

26. Brochet M, Rusniok C, Couvé E, Dramsi S, Poyart C, Trieu-Cuot P, Kunst F Glaser $P$ : Shaping a bacterial genome by large chromosomal replacements, the evolutionary history of Streptococcus agalactiae. Proc Natl Acad Sci USA 2008, 105:15961-15966.

27. Siezen RJ, Starrenburg MJ, Boekhorst J, Renckens B, Molenaar D, van Hylckama Vlieg JE: Genome-scale genotype-phenotype matching of two Lactococcus lactis isolates from plants identifies mechanisms of adaptation to the plant niche. Appl Environ Microbiol 2008, 74:424-436.

28. Cai $H$, Thompson R, Budinich MF, Broadbent JR, Steele JL: Genome sequence and comparative genome analysis of Lactobacillus casei: insights into their niche-associated evolution. Genome Biol Evol 2009, 1:239-257.

29. Gaffé J, McKenzie C, Maharjan RP, Coursange E, Ferenci T, Schneider D: Insertion sequence-driven evolution of Escherichia coli in chemostats. J Mol Evol 2011, 72:398-412.

30. Cai H, Rodríguez BT, Zhang W, Broadbent JR, Steele JL: Genotypic and phenotypic characterization of Lactobacillus casei strains isolated from different ecological niches suggests frequent recombination and niche specificity. Microbiology 2007, 153:2655-2665.

31. Fox PF, McSweeney PLH: Cheese: an overview. In Cheese: Chemistry, Physics and Microbiology. 3rd edition. Edited by Fox PF, McSweeney PLH, Cogan TM, Guinee TP. San Diego: Elsevier; 2004:1-37.

32. Bolotin A, Quinquis B, Renault P, Sorokin A, Ehrlich SD, Kulakauskas S, Lapidus A, Goltsman E, Mazur M, Pusch GD, Fonstein M, Overbeek R, Kyprides N, Purnelle B, Prozzi D, Ngui K, Masuy D, Hancy F, Burteau S, Boutry M, Delcour J, Goffeau A, Hols P: Complete sequence and comparative genome analysis of the dairy bacterium Streptococcus thermophilus. Nat Biotechnol 2004, 22:1554-1558.

33. Hols P, Hancy F, Fontaine L, Grossiord B, Prozzi D, Leblond-Bourget N, Decaris B, Bolotin A, Delorme C, Dusko Ehrlich S, Guédon E, Monnet V, Renault P, Kleerebezem M: New insights in the molecular biology and physiology of Streptococcus thermophilus revealed by comparative genomics. FEMS Microbiol Rev 2005, 29:435-463.

34. van de Guchte M, Penaud S, Grimaldi C, Barbe V, Bryson K, Nicolas P, Robert C, Oztas S, Mangenot S, Couloux A, Loux V, Dervyn R, Bossy R, Bolotin A, Batto JM, Walunas T, Gibrat JF, Bessières P, Weissenbach J, Ehrlich SD, Maguin E: The complete genome sequence of Lactobacillus bulgaricus reveals extensive and ongoing reductive evolution. Proc Natl Acad Sci USA 2006, 103:9274-9279.

35. Callanan M, Kaleta P, O'Callaghan J, O'Sullivan O, Jordan K, McAuliffe O, Sangrador-Vegas A, Slattery L, Fitzgerald GF, Beresford T, Ross RP: Genome sequence of Lactobacillus helveticus, an organism distinguished by selective gene loss and insertion sequence element expansion. J Bacteriol 2008, 190:727-735.

36. Acedo-Félix E, Pérez-Martínez G: Significant differences between Lactobacillus casei subsp. casei ATCC 393T and a commonly used 
plasmid-cured derivative revealed by a polyphasic study. Int J Syst Evol Microbiol 2003, 53:67-75

37. Hogg JS, Hu FZ, Janto B, Boissy R, Hayes J, Keefe R, Post JC, Ehrlich GD: Characterization and modeling of the Haemophilus influenzae core and supragenomes based on the complete genomic sequences of $\mathrm{Rd}$ and 12 clinical nontypeable strains. Genome Bio/ 2007, 8:R103

38. Rasko DA, Rosovitz MJ, Myers GS, Mongodin EF, Fricke WF, Gajer P, Crabtree J, Sebaihia M, Thomson NR, Chaudhuri R, Henderson IR, Sperandio V, Ravel $\mathrm{J}$ : The pangenome structure of Escherichia coli: comparative genomic analysis of E. coli commensal and pathogenic isolates. J Bacteriol 2008 190:6881-6893.

39. Boissy R, Ahmed A, Janto B, Earl J, Hall BG, Hogg JS, Pusch GD, Hiller LN, Powell E, Hayes J, Yu S, Kathju S, Stoodley P, Post JC, Ehrlich GD, Hu FZ: Comparative supragenomic analyses among the pathogens Staphylococcus aureus, Streptococcus pneumoniae, and Haemophilus influenzae using a modification of the finite supragenome model. BMC Genomics 2011, 12:187.

40. Davie JJ, Earl J, de Vries SP, Ahmed A, Hu FZ, Bootsma HJ, Stol K, Hermans PW, Wadowsky RM, Ehrlich GD, Hays JP, Campagnari AA: Comparative analysis and supragenome modeling of twelve Moraxella catarrhalis clinical isolates. BMC Genomics 2011, 12:70.

41. Ehrlich GD, Ahmed A, Earl J, Hiller NL, Costerton JW, Stoodley P, Post JC, DeMeo P, Hu FZ: The distributed genome hypothesis as a rubric for understanding evolution in situ during chronic bacterial biofilm infectious processes. FEMS Immunol Med Microbiol 2010, 59:269-279.

42. Baumdicker $F$, Hess WR, Pfaffelhuber $P$ : The infinitely many genes model for the distributed genome of bacteria. Genome Biol Evol 2012, 4:443-456.

43. Mazé A, Boël G, Zúñiga M, Bourand A, Loux V, Yebra MJ, Monedero V, Correia $K$, Jacques $N$, Beaufils $S$, Poncet $S$, Joyet $P$, Milohanic $E$, Casarégola $S$, Auffray Y, Pérez-Martínez G, Gibrat JF, Zagorec M, Francke C, Hartke A, Deutscher J: Complete genome sequence of the probiotic Lactobacillus casei strain BL23. J Bacteriol 2010, 192:2647-2648.

44. Zhang W, Yu D, Sun Z, Wu R, Chen X, Chen W, Meng H, Hu S, Zhang H: Complete genome sequence of Lactobacillus casei Zhang, a new probiotic strain isolated from traditional homemade koumiss in Inner Mongolia, China. J Bacteriol 2010, 192:5268-5269.

45. Ai L, Chen C, Zhou F, Wang L, Zhang H, Chen W, Guo B: Complete genome sequence of the probiotic strain Lactobacillus casei BD-II. J Bacteriol 2011, 193:3160-3161.

46. Chen C, Ai L, Zhou F, Wang L, Zhang H, Chen W, Guo B: Complete genome sequence of the probiotic bacterium Lactobacillus casei LC2W. J Bacteriol 2011, 193:3419-3420.

47. Latreille P, Norton S, Goldman BS, Henkhaus J, Miller N, Barbazuk B, Bode HB, Darby C, Du Z, Forst S, Gaudriault S, Goodner B, Goodrich-Blair H, Slater S: Optical mapping as a routine tool for bacterial genome sequence finishing. BMC Genomics 2007, 8:321.

48. Snipen L, Almøy T, Ussery DW: Microbial comparative pan-genomics using binomial mixture models. BMC Genomics 2009, 10:385.

49. Seeliger HPR, Jones D: Genus Listeria. In Bergey's manual of systematic bacteriology. 9th edition. Edited by Sneath PHA, Mair NS, Sharpe ME, Holt JG. Baltimore: Williams and Wilkins; 1986:1235-1245.

50. Goffin P, Deghorain M, Mainardi JL, Tytgat I, Champomier-Vergès MC, Kleerebezem M, Hols P: Lactate racemization as a rescue pathway for supplying D-lactate to the cell wall biosynthesis machinery in Lactobacillus plantarum. J Bacteriol 2005, 187:6750-6761.

51. Siezen RJ, Tzeneva VA, Castioni A, Wels M, Phan HT, Rademaker JL, Starrenburg MJ, Kleerebezem M, Molenaar D, van Hylckama Vlieg JE: Phenotypic and genomic diversity of Lactobacillus plantarum strains isolated from various environmental niches. Environ Microbiol 2010, 12:758-773.

52. Renault $P$, Gaillardin $C$, Heslot $H$ : Role of malolactic fermentation in lactic acid bacteria. Biochimie 1988, 70:375-379.

53. Poolman B, Molenaar D, Smid EJ, Ubbink T, Abee T, Renault PP, Konings WN: Malolactic fermentation: electrogenic malate uptake and malate/ lactate antiport generate metabolic energy. J Bacterio/ 1991, 173:6030-6037.

54. Broadbent JR, Larsen RL, Diebold V, Steele JL: Physiological and transcriptional response of Lactobacillus casei ATCC 334 to acid stress. J Bacteriol 2010, 192:2445-2458.

55. Kankainen M, Paulin L, Tynkkynen S, von Ossowski I, Reunanen J, Partanen P, Satokari R, Vesterlund S, Hendrickx AP, Lebeer S, De Keersmaecker SC,
Vanderleyden J, Hämäläinen T, Laukkanen S, Salovuori N, Ritari J, Alatalo E, Korpela R, Mattila-Sandholm T, Lassig A, Hatakka K, Kinnunen KT, Karjalainen H, Saxelin M, Laakso K, Surakka A, Palva A, Salusjärvi T, Auvinen P, de Vos WM: Comparative genomic analysis of Lactobacillus rhamnosus GG reveals pili containing a human-mucus binding protein. Proc Natl Acad Sci USA 2009, 106:17193-17198.

56. Lebeer S, Claes I, Tytgat HL, Verhoeven TL, Marien E, von Ossowski I, Reunanen J, Palva A, de Vos WM, De Keersmaecker SC, Vanderleyden J: Functional analysis of Lactobacillus rhamnosus GG pili in relation to adhesion and immunomodulatory interactions with intestinal epithelial cells. Appl Environ Microbiol 2012, 78:185-193.

57. Barrangou R, Fremaux C, Deveau H, Richards M, Boyaval P, Moineau S, Romero DA, Horvath P: CRISPR provides acquired resistance against viruses in prokaryotes. Science 2007, 315:1709-1712.

58. Garneau JE, Dupuis ME, Villion M, Romero DA, Barrangou R, Boyaval $P$ Fremaux C, Horvath P, Magadán AH, Moineau S: The CRISPR/Cas bacterial immune system cleaves bacteriophage and plasmid DNA. Nature 2010, 468:67-71

59. Horvath $P$, Barrangou R: CRISPR/Cas, the immune system of bacteria and archaea. Science 2010, 327:167-170.

60. Bhaya D, Davison M, Barrangou R: CRISPR-Cas systems in bacteria and archaea: versatile small RNAs for adaptive defense and regulation. Annu Rev Genet 2011, 45:273-297.

61. Horvath P, Coûté-Monvoisin AC, Romero DA, Boyaval P, Fremaux C, Barrangou R: Comparative analysis of CRISPR loci in lactic acid bacteria genomes. Int J Food Microbiol 2009, 131:62-70.

62. Makarova KS, Haft DH, Barrangou R, Brouns SJ, Charpentier E, Horvath P, Moineau S, Mojica FJ, Wolf Yl, Yakunin AF, van der Oost J, Koonin EV: Evolution and classification of the CRISPR/Cas systems. Nat Rev Microbiol 2011, 9:467-477.

63. Deltcheva E, Chylinski K, Sharma CM, Gonzales K, Chao Y, Pirzada ZA, Eckert MR, Vogel J, Charpentier E: CRISPR RNA maturation by trans-encoded small RNA and host factor RNase III. Nature 2011, 471:602-607.

64. Brouns SJ, Jore MM, Lundgren M, Westra ER, Slijkhuis RJ, Snijders AP, Dickman MJ, Makarova KS, Koonin EV, van der Oost J: Small CRISPR RNAs guide antiviral defense in prokaryotes. Science 2008, 321:960-964.

65. Deveau H, Barrangou R, Garneau JE, Labonté J, Fremaux C, Boyaval P, Romero DA, Horvath P, Moineau S: Phage response to CRISPR-encoded resistance in Streptococcus thermophilus. J Bacteriol 2008, 190:1390-1400.

66. Horvath P, Romero DA, Coûté-Monvoisin AC, Richards M, Deveau H, Moineau S, Boyaval P, Fremaux C, Barrangou R: Diversity, activity, and evolution of CRISPR loci in Streptococcus thermophilus. J Bacteriol 2008, 190:1401-1412.

67. Mojica FJ, Diez-Villasenor C, Garcia-Martinez J, Almendros C: Short motif sequences determine the targets of the prokaryotic CRISPR defence system. Microbiol 2009, 155:733-740.

68. Diancourt L, Passet V, Chervaux C, Garault P, Smokvina T, Brisse S: Multilocus sequence typing of Lactobacillus casei reveals a clonal population structure with low levels of homologous recombination. Appl Environ Microbiol 2007, 73:6601-6611.

69. Barrangou R, Horvath P: CRISPR: New horizons in phage resistance and strain identification. Annu Rev Food Sci Technol 2012, 3:143-162.

70. Andersson AF, Banfield JF: Virus population dynamics and acquired virus resistance in natural microbial communities. Science 2008, 320:1047-1050.

71. Tyson GW, Banfield JF: Rapidly evolving CRISPRs implicated in acquired resistance of microorganisms to viruses. Environ Microbio/ 2008, 10:200-207.

72. Held NL, Whitaker RJ: Viral biogeography revealed by signatures in Sulfolobus islandicus genomes. Environ Microbiol 2009, 11:457-466.

73. Heidelberg JF, Nelson WC, Schoenfeld T, Bhaya D: Germ warfare in a microbial mat community: CRISPRs provide insights into the coevolution of host and viral genomes. PLoS One 2009, 4:e4169.

74. Pride DT, Sun CL, Salzman J, Rao N, Loomer P, Armitage GC, Banfield JF, Relman DA: Analysis of streptococcal CRISPRs from human saliva reveals substantial sequence diversity within and between subjects over time. Genome Res 2011, 21:126-136.

75. Godde JS, Bickerton A: The repetitive DNA elements called CRISPRs and their associated genes: evidence of horizontal transfer among prokaryotes. J Mol Evol 2006, 62:718-729.

76. Marraffini LA, Sontheimer EJ: CRISPR interference limits horizontal gene transfer in staphylococci by targeting DNA. Science 2008, 322:1843-1845. 
77. Hale CR, Zhao P, Olson S, Duff MO, Graveley BR, Wells L, Terns RM, Terns MP: RNA-guided RNA cleavage by a CRISPR RNA-Cas protein complex. Cell 2009, 139:945-956.

78. Goh YJ, Zhang C, Benson AK, Schlegel V, Lee JH, Hutkins RW: Identification of a putative operon involved in fructooligosaccharide utilization by Lactobacillus paracasei. Appl Environ Microbiol 2006, 72:7518-7530.

79. Goh YJ, Lee JH, Hutkins RW: Functional analysis of the fructooligosaccharide utilization operon in Lactobacillus paracasei 1195. Appl Environ Microbiol 2007, 73:5716-5724.

80. Riley MA, Lizotte-Waniewski M: Population genomics and the bacterial species concept. Methods Mol Biol 2009, 532:367-377.

81. Darling AE, Mau B, Perna NT: ProgressiveMauve: Multiple genome alignment with gene gain, loss, and rearrangement. PLoS One 2010, 5:e11147.

82. Glasner JD, Liss P, 3rd Plunkett G, Darling A, Prasad T, Rusch M, Byrnes A Gilson M, Biehl B, Blattner FR, Perna NT: ASAP, a systematic annotation package for community analysis of genomes. Nucleic Acids Res 2003, 31:147-151.

83. Tamura K, Dudley J, Nei M, Kumar S: MEGA4: Molecular Evolutionary Genetics Analysis (MEGA) software version 4.0. Mol Biol Evol 2007, 24:1596-1599.

84. Takezaki N, Figueroa F, Zaleska-Rutczynska Z, Takahata N, Klein J: The phylogenetic relationship of tetrapod, coelacanth, and lungfish revealed by the sequences of forty-four nuclear genes. Mol Biol Evol 2004, 21:1512-1524

85. Zhang J, Rosenberg HF, Nei M: Positive Darwinian selection after gene duplication in primate ribonuclease genes. Proc Natl Acad Sci USA 1998, 95:3708-3713.

86. Doolittle RF, Feng DF, Tsang S, Cho G, Little E: Determining divergence times of the major kingdoms of living organisms with a protein clock. Science 1996, 271:470-477.

87. Lawrence JG, Ochman H: Molecular archaeology of the Escherichia coli genome. Proc Natl Acad Sci USA 1998, 95:9413-9417.

88. Li L, Stoeckert CJ Jr, Roos DS: OrthoMCL: identification of ortholog groups for eukaryotic genomes. Genome Res 2003, 13:2178-2189.

89. Altschul SF, Madden TL, Schäffer AA, Zhang J, Zhang Z, Miller W, Lipman DJ: Gapped BLAST and PSI-BLAST: a new generation of protein database search programs. Nucleic Acids Res 1997, 25:3389-3402.

90. Grissa I, Vergnaud G, Pourcel C: CRISPRFinder: a web tool to identify clustered regularly interspaced short palindromic repeats. Nucleic Acids Res 2007, 35:W52-W57.

91. Sonnhammer EL, Durbin R: A dot-matrix program with dynamic threshold control suited for genomic DNA and protein sequence analysis. Gene 1995, 167:GC1-GC10.

92. Altschul SF, Gish W, Miller W, Myers EW, Lipman DJ: Basic local alignment search tool. J Mol Biol 1990, 215:403-410.

93. Crooks GE, Hon G, Chandonia JM, Brenner SE: WebLogo: a sequence logo generator. Genome Res 2004, 14:1188-1190.

94. Cote R, Gherna RL: Nutrition and Media. In Methods for General Molecular Bacteriology. Edited by Gerhardt P, Murray RGE, Wood WA. Washington, DC: American Society for Microbiology; 1994:158.

95. Miles AA, Misra SS: The estimation of the bactericidal power of blood. J Hyg 1938, 38:732-749.

\section{doi:10.1186/1471-2164-13-533}

Cite this article as: Broadbent et al:: Analysis of the Lactobacillus casei supragenome and its influence in species evolution and lifestyle adaptation. BMC Genomics 2012 13:533.

\section{Submit your next manuscript to BioMed Central and take full advantage of:}

- Convenient online submission

- Thorough peer review

- No space constraints or color figure charges

- Immediate publication on acceptance

- Inclusion in PubMed, CAS, Scopus and Google Scholar

- Research which is freely available for redistribution 